\title{
Chamber Music Fundamentals and Rehearsal Techniques for Advancing String Students
}

\author{
Gabrielle Padilla \\ gap0013@mix.wvu.edu
}

Follow this and additional works at: https://researchrepository.wvu.edu/etd

Part of the Music Pedagogy Commons, and the Music Performance Commons

\section{Recommended Citation}

Padilla, Gabrielle, "Chamber Music Fundamentals and Rehearsal Techniques for Advancing String Students" (2021). Graduate Theses, Dissertations, and Problem Reports. 10265.

https://researchrepository.wvu.edu/etd/10265

This Dissertation is protected by copyright and/or related rights. It has been brought to you by the The Research Repository @ WVU with permission from the rights-holder(s). You are free to use this Dissertation in any way that is permitted by the copyright and related rights legislation that applies to your use. For other uses you must obtain permission from the rights-holder(s) directly, unless additional rights are indicated by a Creative Commons license in the record and/ or on the work itself. This Dissertation has been accepted for inclusion in WVU Graduate Theses, Dissertations, and Problem Reports collection by an authorized administrator of The Research Repository @ WVU.

For more information, please contact researchrepository@mail.wvu.edu. 
Chamber Music Fundamentals and Rehearsal Techniques for Advancing String Students

Gabrielle Padilla

\author{
A Research Document submitted \\ to the College of Creative Arts \\ at West Virginia University \\ in partial fulfillment of the requirements for the degree of \\ Doctor of Musical Arts in \\ Viola Performance
}

Andrea Priester Houde, MM, GPD, Chair and Research Advisor

Andrew Kohn, $\mathrm{PhD}$

Michael Vercelli, DMA

Beth Royall, MM, MLIS

School of Music

Morgantown, West Virginia

2021

Keywords: Chamber Music, String Quartet, Chamber Music Rehearsal Techniques, Chamber Music Fundamentals, Intermediate-level Chamber Music, Chamber Music Pedagogy

Copyright 2021 Gabrielle Padilla 


\begin{abstract}
Chamber Music Fundamentals and Rehearsal Techniques for Advancing String Students
\end{abstract}

Gabrielle Padilla

Chamber music pedagogy is an area that is crucial to a comprehensive music education. There is no manual when it comes to chamber music rehearsal or coaching techniques. Many of the great quartets have biographies written on them, yet few shed light on how the quartet handled the problem-solving processes used during rehearsal. This could be due to the longstanding tradition of string quartet education which uses a coach or leader who shares their wisdom and techniques, often as they had learned as young chamber musicians. Without this guidance, young quartets (and sometimes coaches) often have few ideas of how to operate and rehearse on their own. This document will present new/varied rehearsal techniques for students and teachers to incorporate into their rehearsal and coaching spaces specifically at the intermediate-level. It is my hope that this document will supplement the string quartet traditions and be an addition to chamber music pedagogy. Finally, this research will increase the number of resources available for educators, chamber musicians, and performers. 
For my supportive family

For my teachers

For my past, present, and future students 


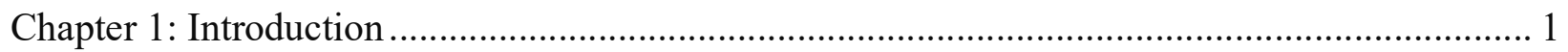

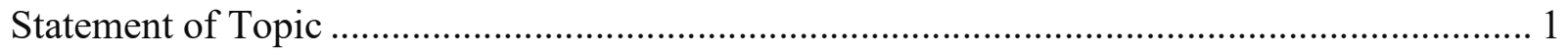

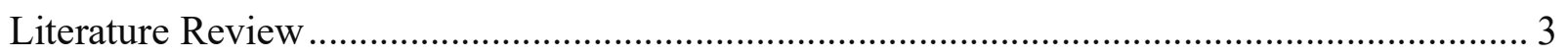

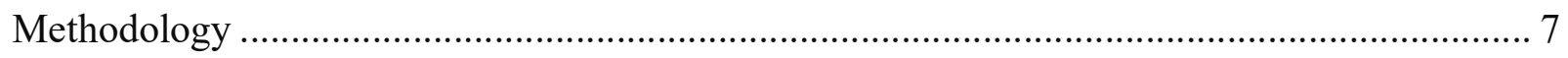

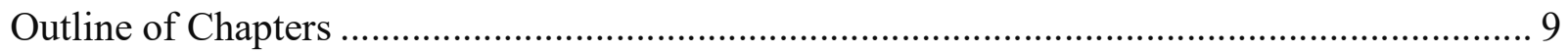

Chapter 2: Past and Present: A Brief History of the String Quartet ....................................... 10

Chapter 3: Chamber Music Fundamentals............................................................................ 19

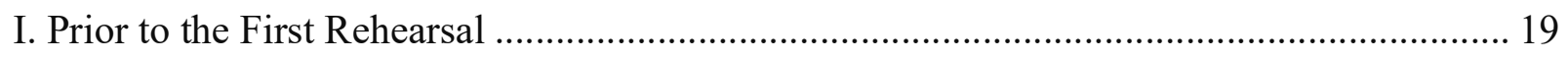

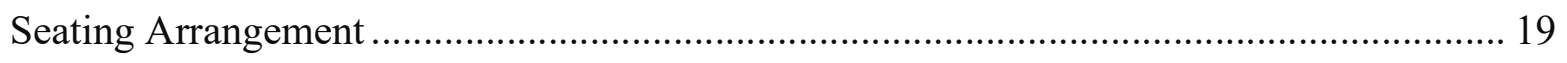

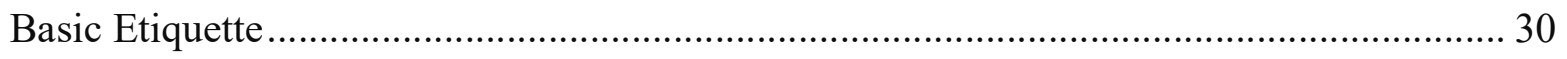

Upholding Democracy within the Quartet.............................................................. 31

Preparation before the First Rehearsal.................................................................. 31

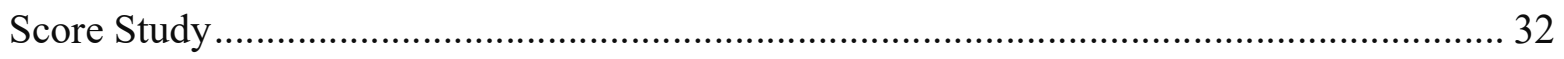

Choosing Repertoire: A Note for Coaches ................................................................. 35

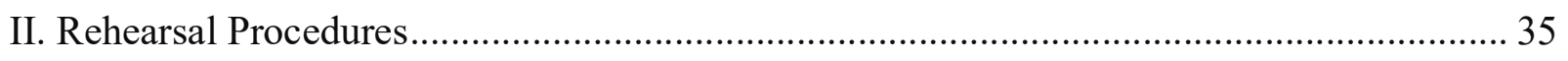

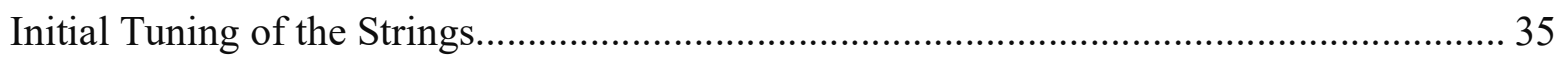

The First Rehearsal or Coaching ............................................................................ 37

Ensemble Communication During Rehearsal........................................................... 38

General Rehearsal Procedures ..................................................................................... 39

Making Interpretive Musical Decisions as an Ensemble.............................................. 41

Chapter 4: Chamber Music Rehearsal Techniques............................................................... 43

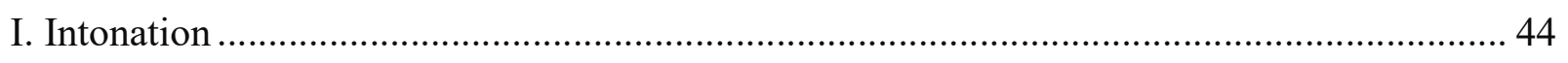

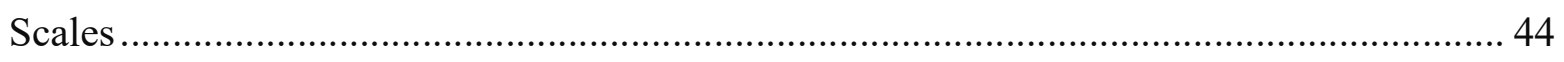

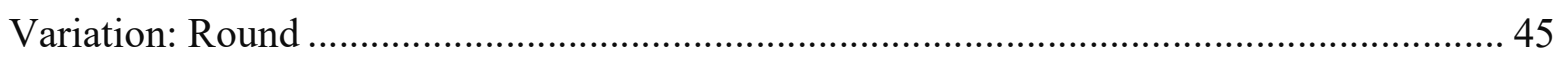

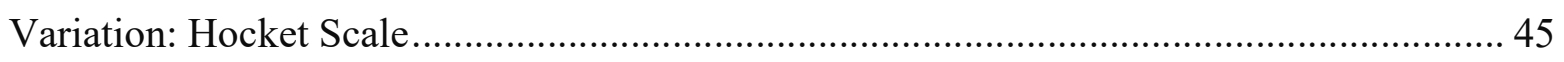

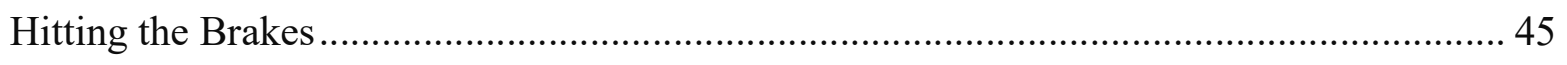

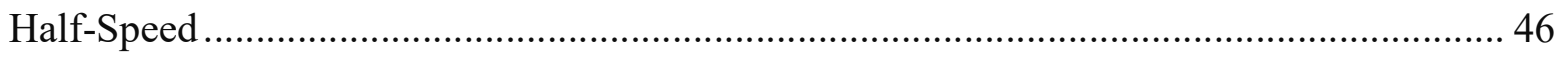

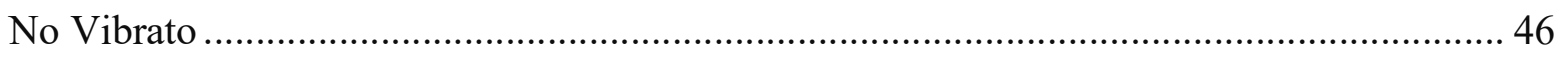

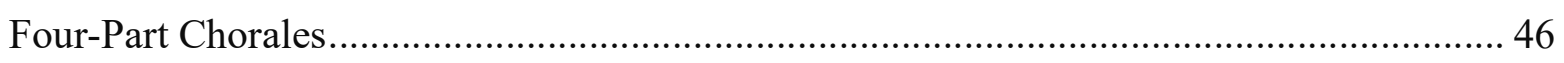

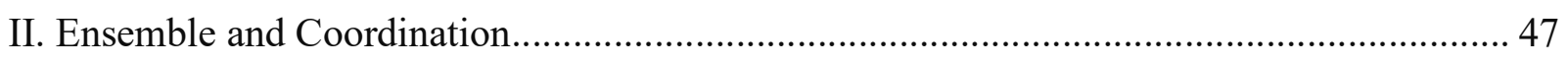

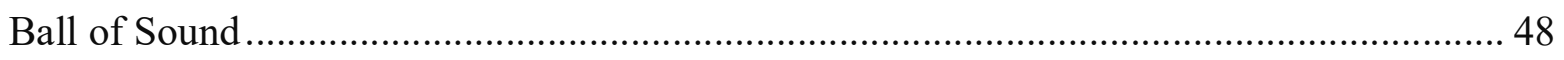

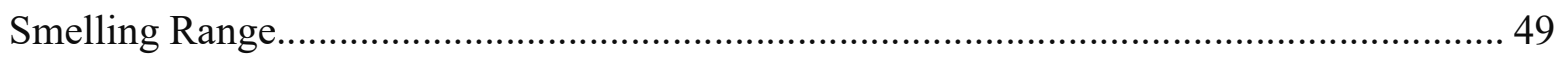

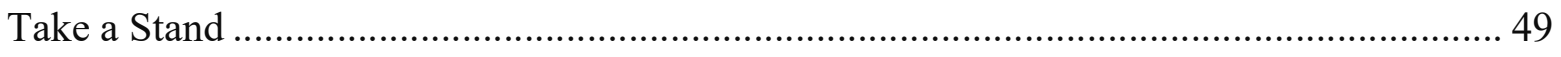




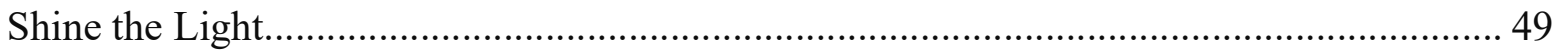

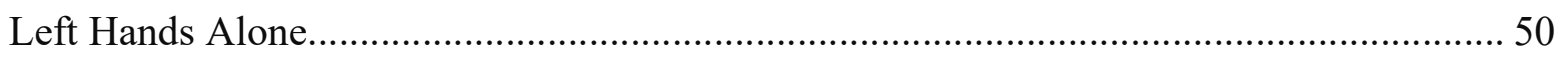

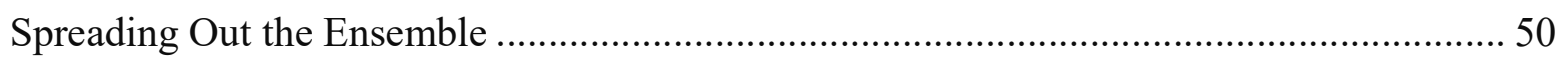

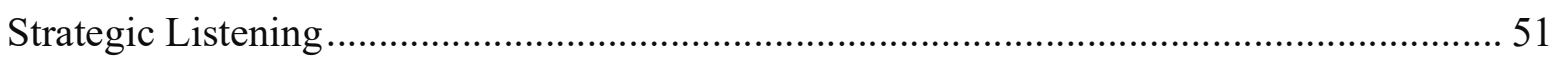

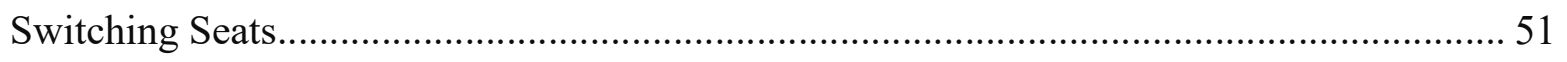

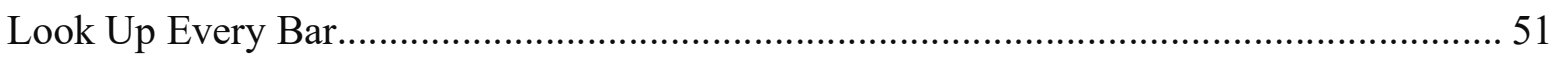

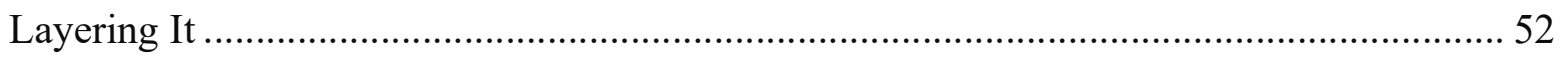

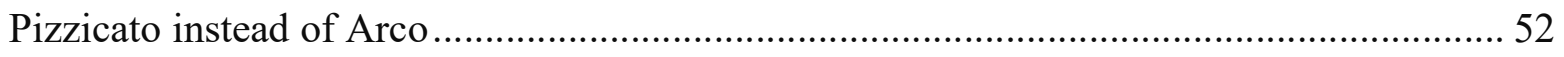

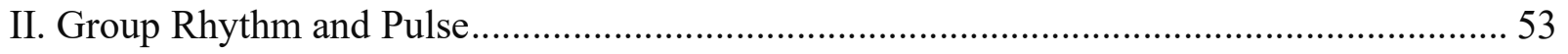

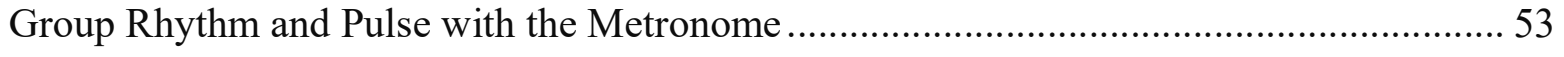

Changing the Metronome's Pulse ................................................................................ 53

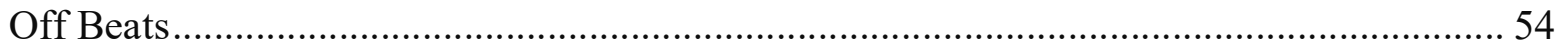

Group Rhythm and Pulse without the Metronome ......................................................... 54

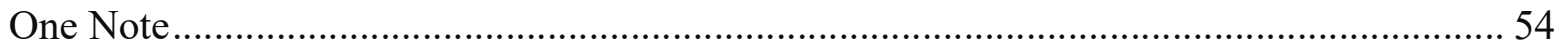

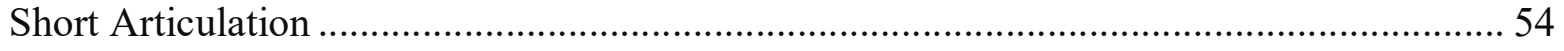

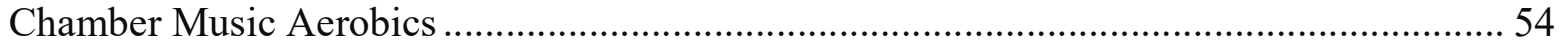

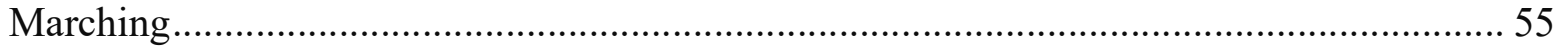

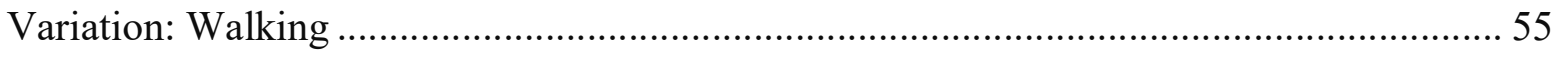

Human Metronome

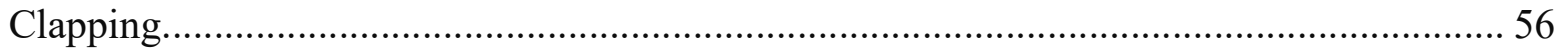

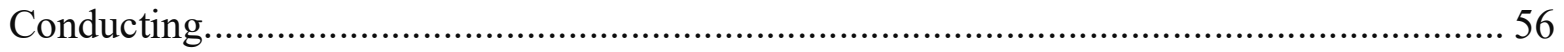

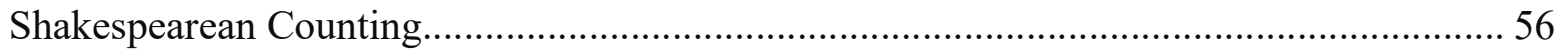

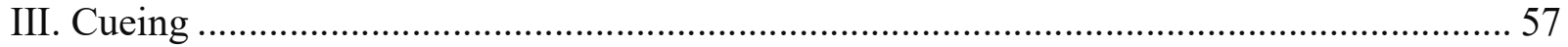

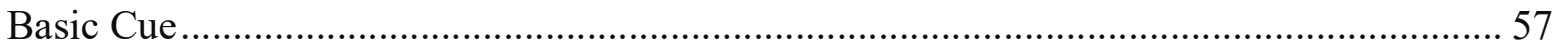

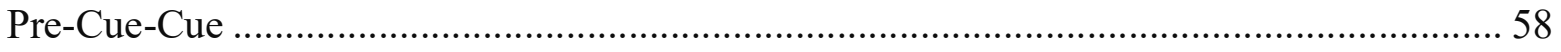

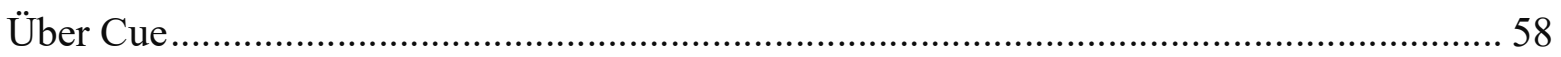

"Live, Breathe, and Die": Cueing and Rhythmic Initiation ............................................... 59

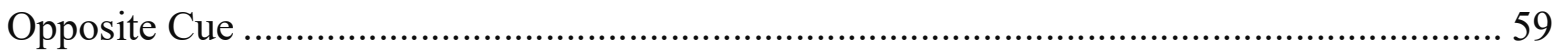

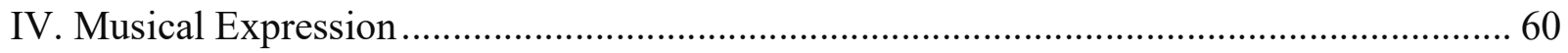

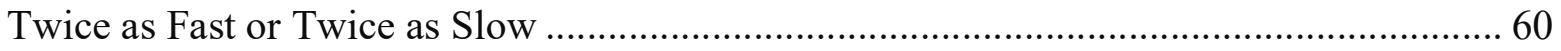

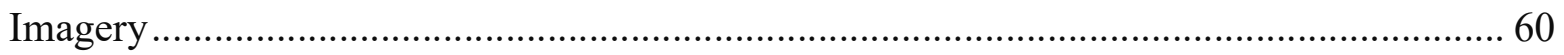

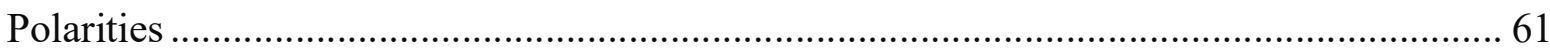

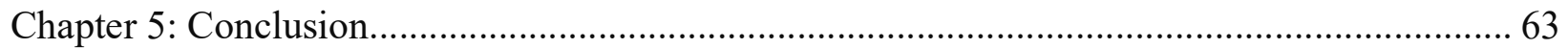

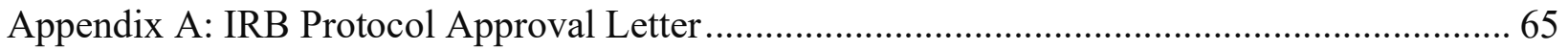




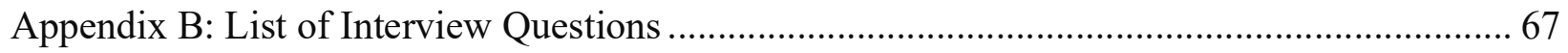

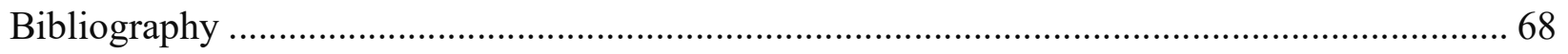




\section{List of Figures}

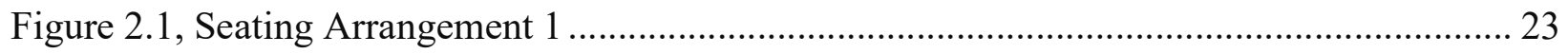

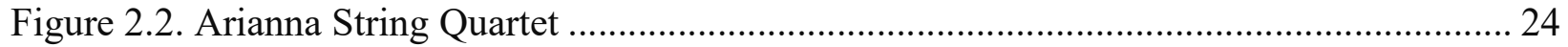

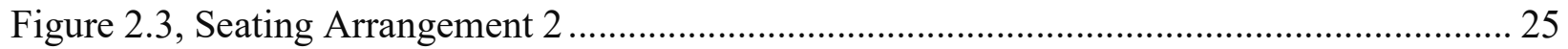

Figure 2.4, Quartet Berlin-Tokyo playing in the Trondheim Chamber Music Festival in 2013 .. 26

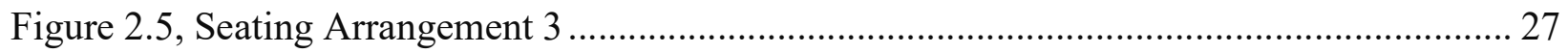

Figure 2.6, Joachim Quartet (1897-1907): (left to right) Joseph Joachim, Robert Hausmann, Emmanuel Wirth, Karel Halír ............................................................................................. 28

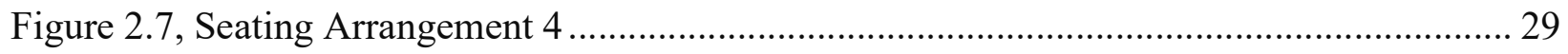

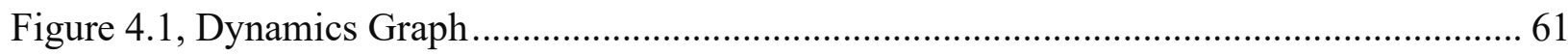




\section{Chapter 1}

Introduction

\section{Statement of Topic}

String chamber music pedagogy is a topic that is becoming increasingly popular. This is an exciting development as chamber music experiences are paramount for students' musical development in many key areas: intonation, pulse, group creativity, creating their unique voice, and leadership, to name a few. We can see the interest in this topic formally developing as many institutions add chamber music degree programs or concentrations with a specialty in string quartet performance. As seen in many movements of specialization, genuine interest tends to grow in both the process and pedagogical aspects of the topic. Currently, there is very little pedagogical information available on chamber music fundamentals and rehearsal techniques. Many of these fundamentals are honed during a chamber music student's intermediate-level development, though some of these skills may still be in the initial stages of learning. Because of the need for pedagogical resources for the learning and teaching of chamber music, especially in this large area of intermediate-student learning, this project's goal is to provide a centralized guide accessible to all string chamber musicians while focusing on chamber music pedagogy specifically for intermediate-level string quartet students.

Intermediate skill-level is potentially difficult to determine and define because of the wide range it encompasses in a student's education. The Oxford Dictionary defines intermediate as the "coming between two things in time, place, order, character, et cetera."1 Within the

\footnotetext{
1 "Intermediate, adj. and n.". OED Online. June 2021. Oxford University Press. https://www-oedcom.wvu.idm.oclc.org/view/Entry/97980.
} 
parameters of this paper's research, an intermediate-level student should be considered neither a beginner, nor a master of their instrument. They should be familiar with basic techniques such as two- and three-octave scales, and should have acquired the skills to perform intermediate-level repertoire, i.e. pieces that are no longer introducing basic musical and technical skills yet are not those considered to be the most challenging masterworks for that instrument. One example might be that an intermediate violinist would be able to perform the Seitz Concerti from Suzuki Violin Method Book 4.

With the previous definitions in mind, the repertoire range of an intermediate-level string quartet ensemble would be from early Luigi Boccherini string quartets (opus 8 and 10); Joseph Haydn string quartets such as op. 76, no. 3, "Emperor", op. 33, no. 3 “The Bird”, and op. 74, no. 3 "Rider"; Wolfgang Amadeus Mozart string quartets such as No. 4 in C major, K. 157, and No. 8 in F major, K. 168; to the Ludwig van Beethoven op. 18 string quartets. Pieces of different time periods are also considered intermediate if they fall within similar technical requirements. One contemporary piece that is appropriate for an intermediate-level string quartet is Butterfly Highway by Ledah Finck. Written in 2017-2018, Butterfly Highway is a string quartet in four movements commissioned by violist and educator Molly Wilkens-Reed during a project focused on the creation of intermediate-level repertoire at the Peabody Conservatory. ${ }^{2}$ Pieces that would be above the range of intermediate level would be works like Beethoven op. 59 or lateMendelssohn string quartets. These pieces would be considered to be advanced-level.

\footnotetext{
${ }^{2}$ Ledah Finck, "Pedagogical Works," Compositions, https://www.ledahfinck.com/compositions.
} 


\section{Literature Review}

Many pedagogical resources include information on the history, traditions, and repertoire of the string quartet, but they rarely discuss the educational transformation and growth process between a beginning student-level ensemble to an advanced-level string quartet ensemble. Within the existing literature, there is a severe lack of published materials that delve into details regarding the fundamentals of rehearsal and performance needed for chamber ensembles to develop and succeed.

While individual musicians use common practice methods such as scales, exercises, and etudes to improve technical components of performance such as intonation, articulation, coordination, and control over phrasing, string quartets must address these same skills as a group. Practice strategies and rehearsal techniques specific to chamber music should address the group's ability to improve these musical skills as a cohesive unit, so it seems logical that published methods, such as etudes or other studies, would be available to aid in this pursuit. In the area of quartet etudes, only two authors have published collections for the string quartet: Jeno Lener's The Technique of String Quartet Playing (1935), and Alfred Pochon's A Progressive Method of String Quartet Playing (1924), both of which are unfortunately out of print. ${ }^{3}$

Currently, there is no set of standard etudes in print that develop a comprehensive string quartet technique.

For the improvement of intonation and coordination, there is only one publication that focuses on these skills for the string quartet to date: String Quartet Technique by McGill

\footnotetext{
${ }^{3}$ Jeno Lener, The Technique of String Quartet Playing: Score and Parts, (London: Chester, 1935). Alfred Pochon, A Progressive Method of String-Quartet Playing in Two Parts, (New York: G. Schirmer, 1924), http://catalog.hathitrust.org/api/volumes/oclc/68156241.html.
} 
International String Quartet Academy Director André J. Roy. ${ }^{4}$ String Quartet Technique is

organized into two parts: Intonation Exercises and Coordination Exercises. Roy writes,

The work on intonation in a string quartet is based on a careful, indissoluble blending of each of the four independent voices. Through a rigorous set of scales, arpeggios and circle of fifths (with clear explanations on the work to be executed), the string quartet will be able to define its own collective intonation and obtain homogeneity of timbres and equality of voices. These progressive exercises are designed to enhance the quartet members' abilities to respond to one another with the greatest of precision. Through each group of exercises, the leading responsibility is given alternatively to each member of the Quartet. Five groups of exercises (A-E) are given with clear explanations on the work to be executed. Two arrangements of Kreutzer etudes [Nos. 2 and 8] are also given for experienced quartets who wish to greatly increase their coordination dexterity. Individual volumes: To facilitate execution, the Circle of Fifths exercises and the Kreutzer etudes, have been reproduced in individual volumes for each instrument. ${ }^{5}$

Within the same vein, music theorist and composer Dr. Matthew Heap of West Virginia University has begun to write a set of advanced string quartet etudes. Heap stated that his research interests as a theorist are very much pedagogical. ${ }^{6}$ The idea for his Etudes for String Quartet, written in 2020, was first realized when his colleague, cello professor and String Chamber Music Coordinator, Dr. Erin Ellis, suggested that he write a set of string quartet etudes. ${ }^{7}$ The design for these etudes revolves around four issues found in string quartet writing: timbral changes (pizzicato, arco, sul ponticello, sul tasto, and other extended techniques); connecting fast, running passages between instruments; advanced harmonic techniques such as quartal and quintal harmonies, as well as microtones; and metric modulation. ${ }^{8}$ Heap has written four etudes: "If It Smells Like Bach," "Hocket Rocket," "Feel the Rhythm," and "So In Tune."

\footnotetext{
${ }^{4}$ André J Roy, String Quartet Technique (Montreal: Royalton Edition, 2014).

${ }^{5}$ Roy, String Quartet Technique, 5.

${ }^{6}$ Dr. Matthew Heap is an Associate Professor of Theory and Composition at West Virginia University. Matthew Heap, interview with author, May 2021. (Hereafter "Heap interview.")

${ }^{7}$ Dr. Ellis is the Assistant Professor of Cello at West Virginia University.

${ }^{8}$ Richard Franko Goldman, "Current Chronicle," Musical Quarterly 37, no. 1 (January 1951): 83-89. In music, metric modulation is a change in pulse rate (tempo) and/or pulse grouping (subdivision) which is derived from a note value or grouping heard before the change. This term was first described by Richard Franko Goldman for Elliot Carter's Cello Sonata.
} 
Each etude addresses at least one of the compositional techniques that can prove challenging for quartet players. Currently, these etudes are unpublished, but they will soon add to the pedagogical materials available for the string quartet.

While sources on intermediate string quartet pedagogy are scarce, Mara E. Parker's String Quartets: A Research and Information Guide contains a chapter dedicated to "Aspects of Performance" and a subchapter titled "Rehearsal Techniques and Advice." This annotated bibliography led to the discovery of several sources. The latest entry is from 2005, although most of the entries were published prior to 1960. That reveals a gap of more than 40 years of absent materials.

Mary D. Herter Norton, the co-founder of W. W. Norton publishing company, wrote two books on string quartet playing: String Quartet Playing and The Art of String Quartet Playing: Practice, Technique, and Interpretation. ${ }^{10}$ Norton was known for her work as a violinist and translator. She studied with the Kneisel Quartet, a string quartet that was established in Boston, Massachusetts in $1885 .{ }^{11}$ The ensemble existed until 1917 and was considered the leading string quartet in the United States, known for their evenness of tone and precise ensemble playing. ${ }^{12}$ Notably, the Kneisel Quartet premiered Antonín Dvořák’s ‘American’ Quartet and Quintet. ${ }^{13}$

\footnotetext{
${ }^{9}$ Mara E. Parker, "Rehearsal Techniques and Advice," in String Quartets: A Research and Information Guide, (London: Routledge, 2011), 407-11.

${ }^{10}$ M. D. Herter Norton, String Quartet Playing: A New Treatise on Chamber Music, Its Technic and Interpretation (New York: C. Fischer, 1925).

M. D. Herter Norton, The Art of String Quartet Playing: Practice, Technique, and Interpretation (New York: Simon and Schuster, 1962).

${ }^{11}$ Steven Ledbetter, "Kneisel Quartet." Grove Music Online. 2001. https://www-oxfordmusiconlinecom.wvu.idm.oclc.org/grovemusic/view/10.1093/gmo/9781561592630.001.0001/omo-9781561592630-e0000046769.

${ }^{12}$ Ledbetter, "Kneisel Quartet."

${ }^{13}$ Tully Potter, "From Chamber to the Concert Hall," in The Cambridge Companion to the String Quartet, ed. Robin Stowell (Cambridge: Cambridge University Press, 2003), 58.
} 
Norton's first book, String Quartet Playing, contains two chapters of ensemble and rehearsal techniques. ${ }^{14}$ Unfortunately some of the predominant information on these topics reflects the ideals of a bygone era. For example, it presents the role of the first violin as the leader position, which takes away the sense of democracy that is a more current philosophy within quartet playing. Her second book, The Art of String Playing, touches on many aspects of string quartet playing and general instrumental performance. However, it is also a bit outdated and would likely be difficult for a young student to understand because of the general tone of language (written in an academic style 60 years ago). This makes sense in a historical context as the book's audience was written for the serious, well-versed musician rather than a beginner, intermediate, or non-musician. This is unfortunate today, however, because readers outside of an educated audience may not benefit in the same way from the information of the text.

A more recent book discussing string quartet and ensemble playing is Abram Loft's How to Succeed in an Ensemble: Reflections on a Life in Chamber Music. ${ }^{15}$ This book is considered autobiographical because it discusses Loft's experience creating and leaving different ensembles. However, he also tackles pedagogical subjects such as "Rehearsal in the Real and Ideal Worlds," “Teaching Chamber Music," and "The Business Side of Ensemble Life." Topics like these could be beneficial for a more advanced, almost professional quartet.

\section{Loft's other book, Ensemble!: A Rehearsal Guide to Thirty Great Works of Chamber}

Music, discusses some of the great works of the standard repertoire of string ensemble, including string quartet, piano quartet, and piano quintet. ${ }^{16}$ For each work, his guide offers an historical

\footnotetext{
${ }^{14}$ Norton, String Quartet Playing: A New Treatise on Chamber Music, Its Technic and Interpretation.

${ }^{15}$ Abram Loft, How to Succeed in an Ensemble: Reflections on a Life in Chamber Music (Portland: Amadeus Press, 2003).

${ }^{16}$ Abram Loft and Reinhard G Pauly, Ensemble!: A Rehearsal Guide to Thirty Great Works of Chamber Music. (Portland: Amadeus Press, 1992).
} 
outline of the composer and composition, as well as suggestions on how to best navigate the work. Loft offers many tips for the reader including score analysis and a full chapter on rehearsal techniques that are applicable to the pre-professional quartet.

Dorianne Cotter-Lockard's dissertation, Chamber Music Coaching Strategies and Rehearsal Techniques that Enable Collaboration, also has an entire chapter devoted to rehearsal techniques which the internationally-renowned Cavani String Quartet uses while teaching and coaching student string quartets. ${ }^{17}$ The Cavani String Quartet made use of these rehearsal techniques in their work with advanced students during their long-term residency at the Cleveland Institute of Music from 1988-2018. These methods may be implemented at any level and can be beneficial to students of all ages and abilities. ${ }^{18}$ Additionally, the Cavani String Quartet touts Cotter-Lockard's work, The Art of Collaboration, by providing a link to the handout on their website. It includes the rehearsal techniques mentioned above in detail. ${ }^{19}$

\section{Methodology}

When first researching this topic, I asked my research advisor, Professor Andrea Houde, for books and author recommendations that discuss chamber music rehearsal techniques.

Professor Houde encouraged me to also reach out to other contacts such as expert chamber music coaches Dr. Erin Ellis, mentioned previously, and Professor Leonard Schranze, Professor of Viola at the University of Memphis, Violist of the Ceruti Quartet, and Strings and Chamber

\footnotetext{
${ }^{17}$ Dorianne Cotter-Lockard, "Chamber Music Coaching Strategies and Rehearsal Techniques that Enable Collaboration" (PhD diss., Fielding Graduate University, 2012).

18 "Cavani String Quartet Celebrates 30 Years as Artists-In Residence at the Cleveland Institute of Music 19882018," News, Cavani String Quartet, accessed November 18, 2021, https://cavanistringquartet.com/news/cavanistring-quartet-celebrates-30-years-artists-residence-cleveland-institute-music-1988-2018/.

${ }^{19}$ Annie Fullard and Dorianne Cotter-Lockard, "The Art of Collaboration: Creative Chamber Music Rehearsal Techniques \& Musical Team Building.” Cavani String Quartet. 2020. https://cavanistringquartet.com/artcollaboration-seminar/.
} 
Music Coordinator at Interlochen Arts Camp in Interlochen, Michigan. Dr. Ellis and I confirmed the lack of published materials on this topic and concluded that this could be due to the longstanding tradition of the string quartet in which a coach or leader passes down his or her wisdom and techniques, as they had learned as young chamber musicians, to the next generation. This hypothesis is verified by Steven Tenenbom, Orion String Quartet violist and faculty of The Juilliard School and Curtis Institute, as he has said that one of the aspects he values most about coaching chamber music is its oral teaching tradition. ${ }^{20}$

As it became apparent that much of the knowledge around chamber music has been shared by oral traditions, I decided to conduct interviews with prominent chamber musicians and coaches to investigate these topics more deeply. Interview requests were sent to selected potential participants based on their expertise, accomplishments, and knowledge in the field of chamber music. The interviews were conducted through Zoom and lasted approximately one hour. An IRB Protocol was submitted which was approved by West Virginia University. The IRB Protocol approval letter and other documentation can be found in the Appendix.

Those who were invited to be interviewed through this process are considered to be among the top of their field in chamber music performance and coaching. Some I know personally: Leonard Schranze, already mentioned above, and Mark Rudolff, cello professor at The Ohio State University. The others interviewed include a founding-violinist of the Cavani Quartet, Susan Waterbury; Melinda Daetsch, faculty of viola, chamber music, and pedagogy at the Hartt School and the Chair of Chamber Music at the Hartt Community Division; Dr. Lauretta Werner, Assistant Professor of Strings at Longwood University; Dr. Erin Ellis; and Dr. Matthew

\footnotetext{
${ }^{20}$ Heather K. Scott, "Refine Your Ensemble’s Sound by Hiring a Coach,” Strings no. 200 (December 2011): 37.
} 
Heap. The participants for this research were selected based on their experience as chamber music coaches and their availability.

These requests resulted in seven interviews, all of which provided information for this document. Interview topics covered set up, tuning of strings, rehearsal techniques, chamber music procedures and etiquette, and musical interpretation. The list of interview questions can be viewed in Appendix B.

\section{Outline of Chapters}

This document includes the following five chapters: (1) introduction of this research, (2) exploring the history of the string quartet, (3) discussing the fundamentals of string quartet playing: prior to the first rehearsal and rehearsal procedures, (4) rehearsal techniques, and (5) a conclusion. 


\section{Chapter 2}

\section{Past and Present: A Brief History of the String Quartet}

\section{Chamber music has provided a means for sharing - blending one's part with the whole and at} the same time retaining a worthwhile identity. ${ }^{21}$

The study of the history of the string quartet gives perspective to the ensembles of today by connecting them with the past. By looking at the origins of the artform, musicians can make informed decisions in their music-making, preserving ideas of the past, and evolving toward the future. Steered by these decisions, the string quartet and its repertoire have accumulated several hundred years of history at this point, and yet it has continued to make its mark in Western Art Music and even in other musical traditions. The following discussion of the history of the string quartet will include: the definition of chamber music, the precursors of the string quartet, the canonization of the repertoire, the beginnings of the professional string quartet, and the trends of today.

Chamber music is based on its instrumentation and the location and function of the music. ${ }^{22}$ The term "chamber music" was first introduced as early as the sixteenth century by theorist Nicola Vicentino in his work L'Antica Musica Ridotta alla Moderna Prattica (1555). ${ }^{23}$ This was presented in three ways: musica ecclesiastica (church music), musica theatralis (theater music), and musica cubicularis (chamber music). ${ }^{24}$ The term has been translated in different languages: "musica da camera" in Italian, "kammermusik" in German, "la musique de la chambre" in French (established at the French Court in 1530), and "cammermusici" at the Court

\footnotetext{
${ }^{21}$ John H. Baron, Intimate Music: A History of the Idea of Chamber Music (Stuyvesant, NY: Pendragon Press, 1998), 440.

${ }^{22}$ Baron, 3.

${ }^{23}$ Baron, 1.

${ }^{24}$ Mark A. Radice, Chamber Music: An Essential History (University of Michigan Press, 2012), 1.
} 
of Maximilian II, Holy Roman Emperor (1540-1600). ${ }^{25}$ According to musicologist and music educator John Herschel Baron, there are five major points that define chamber music:

1. Chamber music is instrumental music.

2. Chamber music is ensemble music, i.e., music for two or more performers.

3. Chamber music is soloistic, i.e., no two players play the same music at the same time.

4. The purpose of this music is to provide serious ensemble, not the virtuosic display of one member of the ensemble (though the latter often intrudes in chamber music).

5. The core feature of any chamber music is its overt or implied intimacy. ${ }^{26}$

It would be difficult to pinpoint exactly where the string quartet began, as it has a long history of changes; however, there are several examples of what could be considered to be precursors of the form. A very early example of an ancestor of the string quartet would be Sinfonia for Strings by Gregorio Allegri (1582-1652). It was the first written work for four individual string instrumental parts. ${ }^{27}$ Another early example of the string quartet is by Alessandro Scarlatti (1660-1725), who wrote a set of six works, Sonata à Quattro per due Violini, Violetta [viola], e Violoncello senza Cembalo, sonata for four instruments: two violins, viola, and cello without harpsichord. This was an evolution from the previous tradition because it omitted the keyboard instrument. The harpsichord was an important continuo instrument during the Baroque and Classical eras; therefore, the removal of the harpsichord could be proof of a distinct shift in the composition and stands as a noteworthy event in the development of the chamber music genre. ${ }^{28}$

Another form that serves as a precursor to the string quartet was the Baroque trio sonata. This form was an ensemble of two solo instruments performing alongside a

\footnotetext{
${ }^{25}$ Radice, 1.

${ }^{26}$ Baron, 6.

${ }^{27}$ Paul Griffiths, The String Quartet. (New York: Thames and Hudson, 1983), 7.

${ }^{28}$ Griffiths, 8.
} 
continuo section that contained a bass instrument. The continuo section could include a viola da gamba or cello, and a keyboard instrument. ${ }^{29}$ In this context, the term "trio" can be confusing, as this ensemble can consist of three or four performers. By the early eighteenth century, composers were often adding a third soloist, typically the viola, and it became commonplace to exclude the keyboard part which allowed the cello to support the bass line alone, as seen in Scarlatti's work. ${ }^{30}$ Trio sonatas were composed by many composers such as Arcangelo Corelli, Dieterich Buxtehude, and Georg Philipp Telemann to name a few.

Similar to the example of Scarlatti reducing the continuo section in his string ensemble, the practice of scaling down orchestral sectional parts to one instrument per part produced works for two violins, viola, and cello that became popularized as well. ${ }^{31}$ Composers such as Arcangelo Corelli (1653-1713), Giuseppe Torelli (1658-1709), Antonio Vivaldi (1678-1741), and Giovanni Sammartini (1700/01-1775) all wrote these types of works. Sammartini, who is frequently left out of the conversation in the history of the string quartet, first began reducing four-part string orchestra works in the 1730 s. He then wrote works considered to be early string quartets (17631767) and string quintets (1773). The early string quintets were scored for three violins, viola, and bass. ${ }^{32}$ It is important to recognize that an eighteenth-century piece that calls for "bass" is

\footnotetext{
${ }^{29}$ Sandra Mangsen, "Trio Sonata," Grove Music Online. 2001, Accessed May 27, 2021. https://wwwoxfordmusiconline-com.wvu.idm.oclc.org/grovemusic/view/10.1093/gmo/9781561592630.001.0001/omo9781561592630-e-0000028382.

${ }^{30}$ David Wyn Jones, "The Origins of the Quartet," in The Cambridge Companion to the String Quartet, ed. Robin Stowell (Cambridge: Cambridge University Press, 2003), 178.

${ }^{31}$ Jones, 179.

${ }^{32}$ Bathia Churgin, "Sammartini [S. Martino, S. Martini, St. Martini, St. Martino, San Martini, San Martino, Martini, Martino], Giovanni Battista." Grove Music Online. 2001; Accessed 19 May. 2021. https://www-oxfordmusiconlinecom.wvu.idm.oclc.org/grovemusic/view/10.1093/gmo/9781561592630.001.0001/omo-9781561592630-e0000024463 .
} 
often not being specific about which instrument is meant: it is a function, rather than an instrument. ${ }^{33}$

The mid-1700s were known as a transitional age in music that led to a lack of classification of ensembles. There were various terminologies for the forms of chamber music being written, including divertimento, serenade, notturno, and cassation. ${ }^{34}$ The divertimento was designed to be used as entertainment for the listeners and to denote an instrumental work written for one or more solo players. ${ }^{35}$ There are examples of divertimenti for two solo violins, viola, and cello by Viennese composers such as Ignaz Holzbauer (1711-1783) and Wolfgang Amadeus Mozart (1756-1791). ${ }^{36}$ The divertimento ultimately paved the way for the development of the string quartet.

Other examples that advanced the development of the string quartet were works by Georg Matthais Monn (1717-1750) and Georg Christoph Wagenseil (1715-1777). Both wrote symphonies for four-parts alone. ${ }^{37}$ Again, these works were composed for a larger ensemble, but could be performed by four individuals. Monn wrote fifteen four-part works for string orchestra titled Sinfonia a Quattro and Quartetto. Six of these works were published many years later at the beginning of the nineteenth century by the publisher Bureau des Arts et d'Industrie. They were issued as quartets and were intended to be performed alongside the orchestral and symphonic works of Haydn, Mozart, and Beethoven in the concert halls. ${ }^{38}$ Since there was no

\footnotetext{
${ }^{33}$ James Webster, "Violoncello and Double Bass in the Chamber Music of Haydn and His Viennese Contemporaries, 1750-1780," Journal of the American Musicological Society 29, no. 3 (1976): 424-5.

34 Griffiths, 8.

${ }^{35}$ Unverricht, Hubert, and Cliff Eisen, "Divertimento." Grove Music Online. 2001; Accessed 5 Dec. 2021. https://www-oxfordmusiconlinecom.wvu.idm.oclc.org/grovemusic/view/10.1093/gmo/9781561592630.001.0001/omo-9781561592630-e0000007864.

${ }^{36}$ Jones, $180-1$.

${ }^{37}$ Jones, 180.

${ }^{38}$ Jones, 180.
} 
distinction between orchestral and chamber music works, many compositions could be marketed as both a symphony and a quartet, therefore potentially increasing the publisher's profits. ${ }^{39}$

It is universally thought that the string quartet came into full existence during the life of Franz Joseph Haydn (1732-1809). In fact, he is nicknamed the Father of the Symphony and the Father of the String Quartet. ${ }^{40}$ Writer Georg August Griesinger may have contributed to this monumental image of Haydn by publishing Haydn's biography after his death in eight installments, later published into one single document. ${ }^{41}$ Griesinger's book helped build the image of Haydn in much the same way as Johann Nikolaus Forkel's biography of Johann Sebastian Bach created the image of Bach's "genius" we accept today. Regardless of the truth behind this debate, Haydn's prolific output in the genre produced some of the most revered, studied, and performed chamber works in existence.

Haydn's ten early string quartets are dedicated to Baron Fünberg. ${ }^{42}$ It is estimated that Haydn wrote his first ten string quartets between 1757 and 1762. As stated before, Haydn did not invent the combination of two violins, viola, and cello, which is closely related to the Austrian divertimento tradition, a lighthearted piece written specifically for a small ensemble to be played at a social function. Haydn's plentiful writing for two violins, viola, and cello helped the string quartet genre gain momentum and popularity.

String quartet composition took off in a number of European cultural centers, but there was not a unified form regarding the structure of movements at that time. Haydn's early quartets followed the scheme of five movements: presto movement, minuet, central slow movement,

\footnotetext{
${ }^{39}$ Griffiths, 8.

${ }^{40}$ Georg Feder, and James Webster, "Haydn, (Franz) Joseph." Grove Music Online. 2001; Accessed 19 May. 2021. https://www-oxfordmusiconline-

com.wvu.idm.oclc.org/grovemusic/view/10.1093/gmo/9781561592630.001.0001/omo-9781561592630-e-

0000044593.

${ }^{41}$ Jones, 177.

42 Feder, "Haydn, (Franz) Joseph."
} 
minuet, and a final presto movement. That pattern changed in Haydn's opus 20 string quartets which unintentionally set the standard for quartet writing. These works featured equality of voices among instruments, the use of ternary form, and fugal finales. Haydn's opus 20 quartets are marked as the first "true" string quartets, thus making works composed prior to this a predecessor. The opus 20 and opus 33 quartets represent a distinct shift in the overall planning of the movements. The structure consisted of four movements: the first movement, an allegro in the tonic key and in ternary form; the slow movement, in a closely related key; a minuet and trio; and a final fourth movement, often in rondo form or sonata rondo form, in the tonic key. Along with this seeming maturation, the string quartet as a compositional genre began to flourish in the Classical and Romantic eras. Wolfgang Amadeus Mozart, Ludwig van Beethoven, and Franz Schubert all composed a wealth of quartet music that is now considered a part of the canon.

Some of the successes of chamber music as a genre may be attributed to financial reasons: the low cost and ease of rehearsal. Pre-formed groups were less expensive than hiring an entire orchestra and came pre-rehearsed. From a business standpoint, this was something worth investing in. The first public chamber music concerts were held by John Banister from 16721678 in his London home. ${ }^{43}$ It is thought that these concerts must have been well-supported and well-attended to have lasted that long. ${ }^{44}$ By the early 19 th century, public concerts dedicated to full-length chamber music programs, with some concerts featuring a single string quartet ensemble, were becoming increasingly popular. Audiences formed around groups of enthusiastic amateur practitioners, and performances were financially protected by subscription lists, an arrangement in which a patron would essentially sponsor a musician or a quartet. As patrons

\footnotetext{
${ }^{43}$ Griffith, 11.

${ }^{44}$ Hugh Arthur Scott, "London's Earliest Public Concerts," The Musical Quarterly 22, no. 4 (1936): 457. Accessed May 14, 2021. http://www.jstor.org/stable/738953.
} 
continued their financial support for ensembles, this ushered in the era of the professional string quartet, which had never been seen before.

With the popularization of the string quartet as a genre, professional quartets began to emerge. Ignaz Schuppanzigh is often linked with the history of the first professional string quartet. Schuppanzigh was first seen with an informal ensemble for Prince Lichnowsky's court in Austria and later at Count Razumovsky’s court in Russia. ${ }^{45}$ In 1808, Ignaz Schuppanzigh founded the Schuppanzigh Quartet which is marked as being the first professional string quartet in history. Ignaz Schuppanzigh at Count Razumovsky’s court (1804-1805), Karl Möser's quartet in Berlin (1813-1814), and Pierre Baillot's Séances de Quatuors et Quintetts in Paris (1814) were some of the most established professional string quartet groups of this time. ${ }^{46}$

As an important side-note, it is difficult to find examples of women string quartet musicians before the 1890 s. Perhaps this is due to the limited number of sources contained in this subject matter, or to the masculine association with the playing of stringed instruments in previous centuries. The change regarding female string instrumentalists began in the late $19^{\text {th }}$ century as American violinist Maud Powell emerged as one of the first women to be internationally-recognized as a soloist. Powell also became one of the first women to form and lead a string quartet. ${ }^{47}$ The Maud Powell Concert Company, which was formed by Powell, consisted of a group of six musicians, and included Maud Powell Trio, with the company's

\footnotetext{
${ }^{45}$ K.M. Knittel, "Schuppanzigh, Ignaz," Grove Music Online. 2001, https://www-oxfordmusiconlinecom.wvu.idm.oclc.org/grovemusic/view/10.1093/gmo/9781561592630.001.0001/omo-9781561592630-e0000025160 .

${ }^{46}$ Christina Bashford, "The String Quartet and Society," in The Cambridge Companion to the String Quartet, ed. Robin Stowell (Cambridge: Cambridge University Press, 2003), 7.

${ }^{47}$ Karen A. Shaffer, "Powell, Maud," Grove Music Online. 2001, Accessed June 17, 2021. https://wwwoxfordmusiconline-com.wvu.idm.oclc.org/grovemusic/view/10.1093/gmo/9781561592630.001.0001/omo9781561592630-e-0000043691.
} 
cellist May Mukle and pianist Anne Mukle Ford. Both groups traveled within the United States and South Africa. ${ }^{48}$

During the beginning of the twentieth century, music underwent many drastic developments both musically and technologically. There were several ways in which compositional styles changed, such as the use of form, color, and harmony, but there were also social and economic changes that led to new paths for both the private and public concert performance. After World War II, there was an influx of professional quartets from Europe that came to the United States such as the Amadeus Quartet, Budapest String Quartet, Takács Quartet, and Quartetto Italiano, to name a few. ${ }^{49}$ Audiences began to see the quartet recital become an established event due to growing chamber music societies, booked ensembles, touring of American universities, and summer festivals. ${ }^{50}$ Technological advancements such as the radio, television, and video forever changed the way composers, performers, and audiences alike interact with one another. The world was quite literally an established quartet's stage due to the availability of records and radio broadcasts.

Throughout the twentieth century, the repertoire of the string quartet saw some of its most bold advancements. Several composers found their own unique compositional styles and displayed them using the string quartet as a medium. The genre played a role in the development of Arnold Schoenberg, Béla Bartók, and Dmitri Shostakovich. Schoenberg created his system of atonality through the use of twelve-tone technique, Paul Hindemith and Igor Stravinsky pressed forward with neoclassicism, and Bartók created a new system of consonance and dissonance. ${ }^{51}$ Bartók's string quartets were almost immediately accepted into the repertoire through his

\footnotetext{
48 Shaffer, "Powell, Maud."

49 Bashford, 14.

${ }^{50}$ Bashford, 15.

51 Baron, 380.
} 
experimentation of tone colors, forms, and rhythmic vitality. ${ }^{52}$ Bartók's notable quartet, String

Quartet No. 4, is a symmetrical five-movement work which is echoed throughout the quartet as a whole. His String Quartet No. 5 followed suit with symmetry, but instead of a slow middle movement, Bartók placed a scherzo as the central movement. ${ }^{53}$

Today's string quartet repertoire includes what are considered to be traditional standard works of the repertoire, often referred to as the works of Haydn and Beethoven, as well as those by Brahms and Bartók, while also containing works from beyond the realm of traditional chamber music. Outside of the classical canon, the Kronos Quartet has a famous recording of Jimi Hendrix's Purple Haze,${ }^{54}$ and the Turtle Island String Quartet has performed Dizzy Gillespie's jazz standard A Night in Tunisia. ${ }^{55}$ Additionally, starting in the summer of 2020 as the Black Lives Matter protests swept across the globe, musicians and organizations have been coming together to provide databases and concerts fully dedicated to underrepresented composers that include BIPOC and LGBT+ individuals. ${ }^{56}$ These efforts promise to continue to expand the range of works that are among the standard string quartet literature for the future.

\footnotetext{
${ }^{52}$ Cliff Eisen, Antonio Baldassarre, and Paul Griffiths, "String quartet," Grove Music Online. 2001, Accessed July $12,2021$.

https://www.oxfordmusiconline.com.wvu.idm.oclc.org/grovemusic/view/10.1093/gmo/9781561592630.001.0001/o mo-9781561592630-e-0000040899.

${ }^{53}$ Kenneth Gloag, "The String Quartet in the Twentieth Century," in The Cambridge Companion to the String Quartet, ed. Robin Stowell (Cambridge: Cambridge University Press, 2003), 304.

${ }^{54}$ ohyoi23, "Purple Haze - Kronos Quartet," YouTube Video, 4:29, June 17, 2011, https://www.youtube.com/watch?v=4dE65iTuG4Y.

55 foxfireman188, "A Night in Tunisia - Turtle Island String Quartet," YouTube Video, 8:12, December 20, 2021, https://www.youtube.com/watch?v=XyDE26kle2A.

56 "Underrepresented Composer Database," American Viola Society, accessed May 1, 2021, https://www.americanviolasociety.org/Composer-Database/Search.php.
} 


\section{Chapter 3}

Chamber Music Fundamentals

What does a string quartet need to know as they approach playing together for the first time? What decisions must be made before and during their first rehearsals in preparation for performances? What are the skills an inexperienced ensemble should develop? All of these questions lead to ideas that could be considered to be chamber music fundamentals. These building blocks of chamber music include how to arrange the ensemble and how to prepare for a rehearsal, as well as the nuts and bolts of procedures during rehearsals and how to work together as a group. They are essential for the development of an ensemble and are mostly learned during a chamber music student's intermediate-level stage, though some skills may still be introductory. This chapter will discuss some of these important aspects of string quartet playing. It will be divided into topics to consider Prior to the First Rehearsal (seating arrangement, basic etiquette, upholding democracy, preparation before the first rehearsal, and choosing repertoire) and Rehearsal Procedures (initial tuning of the strings, rehearsal planning, communication, and making interpretive musical decisions as an ensemble). The research for the following chapters is collected from published texts, interviews conducted with chamber music professionals, and the author's personal experiences.

\section{$\underline{\text { I. Prior to the First Rehearsal }}$}

\section{Seating Arrangement}

One of the first decisions a quartet must make is how their seating will be arranged. That choice could be based on several factors like acoustics, balance, traditional practices of the chosen repertoire, or performers' preferences. There are many options regarding seating 
arrangements within a string quartet. Surprisingly, in the interviews held during this project's research, none of the interviewed chamber music coaches were opposed to trying out or experimenting with varying seating arrangements. While everyone had their personal preferences, there was not a standard seating arrangement that is considered superior for all groups.

The choices for seating in a string quartet have evolved over history. During the eighteenth century, there is little evidence to suggest the correct way for seating within a string quartet. However, during the nineteenth century, there are historical photographs that demonstrate that plenty of seating arrangements were tried and experimented with. There seemed to be two broad categories for the quartet seating arrangements: the two violins sitting side-byside or facing each other (antiphonal or conversational). ${ }^{57}$

String quartet seating arrangements tend to mimic that of the symphonic orchestra. In the early twentieth century, orchestras were seated with antiphonal, or "conversational," violins. In the mid-twentieth century, the conductor of the Philadelphia Orchestra, Leopold Stokowski, liked to be creative with orchestral seating arrangements. His most innovative seating arrangement was placing the string instruments from high to low, left to right, with the violin sections next to one another and the violas on the inside of the orchestra. This came to be known as "American" seating, and is still used to this day. ${ }^{58}$ Colloquially, the "American" seating arrangement for the string quartet is recognized as placing the viola inside of the quartet. If the

\footnotetext{
${ }^{57}$ Simon Standage, "Historical Awareness in Quartet Performance," in The Cambridge Companion to the String Quartet, ed. Robin Stowell (Cambridge: Cambridge University Press, 2003), 147.

${ }_{58}$ José A. Bowen, "Stokowski, Leopold," Grove Music Online. 2001; Accessed 31 Oct. 2021. https://wwwoxfordmusiconline-com.wvu.idm.oclc.org/grovemusic/view/10.1093/gmo/9781561592630.001.0001/omo9781561592630-e-0000026825.
} 
group is performing a work by an American or Contemporary composer, for example, they might choose a more traditionally "American” set up.

A group's seating may also be influenced by repertoire selection. Many ensembles will choose to have the traditional Classical seating, which seats the violins facing one another. This is also called the "German" or "European" seating. ${ }^{59}$ One of the prolific violinists of the nineteenth century, Joseph Joachim, and the Joachim Quartet in Berlin, implemented this seating arrangement. Conversely, seen towards the twentieth century, the violins are sitting side-by-side with either the viola or cello sitting opposite of the first violin. ${ }^{60}$ There are photos of Joachim in his London quartet also using this opposite seating arrangement.

Professor of Violin at Ithaca College and founding member of the Cavani String Quartet, Susan Waterbury, suggests that a seating arrangement may be based on how repertoire is written and how its musical material is presented. ${ }^{61}$ She used the example of Felix Mendelssohn's Octet which is performed with pre-formed quartets, having each quartet mirror each other with the violins on both ends of the ensemble. Although the Mendelssohn Octet is not considered to be intermediate-level repertoire, it makes an interesting point. An intermediate-level example for the violins to be seated facing each other in this way could be Haydn's String Quartet Op. 76, No. 2 ('Fifths'). Many ensembles might choose the traditional Classical seating because they are performing a German Classical piece, and the group might want to reflect this performance practice- However, the most traditional and standard seating currently is with violin 1 and viola facing each other. In fact, many of the quartets from the mid-twentieth century through to the most popular quartets of today use this seating arrangement.

\footnotetext{
${ }^{59}$ Eisen, "String quartet".

${ }^{60}$ Standage, 147.

${ }^{61}$ Susan Waterbury, interview with author, June 2021. (Hereafter "Waterbury interview.”)
} 
Often, students are very passionate about a particular seating arrangement because they might have seen it modeled on a string quartet's video recording. Watching different video performances can be a great way to begin observing how a group might set up to create different sounds, colors, and balance within the ensemble. From the beginning, it is important to involve the performing students in these choices.

Perhaps the most important factor when determining an ensemble's seating arrangement is how the ensemble desires their overall sound to be perceived by the audience. Both student and professional string quartets can experiment in order to discover what is best for their own group. Leonard Schranze, Professor of Viola at the University of Memphis, mentioned that while studying with Max Aronoff of the Curtis Quartet, the Curtis Quartet went through an experimental phase of seating options but ultimately ended up using the traditional form. ${ }^{62}$

The following examples show the different string quartet seating arrangements and their advantages and disadvantages. Each example features a graphical representation of the seating and an historical photograph of its use. The titles of each arrangement are the creation of the author.

${ }^{62}$ Standage, 147. 


\section{Seating Arrangement 1}

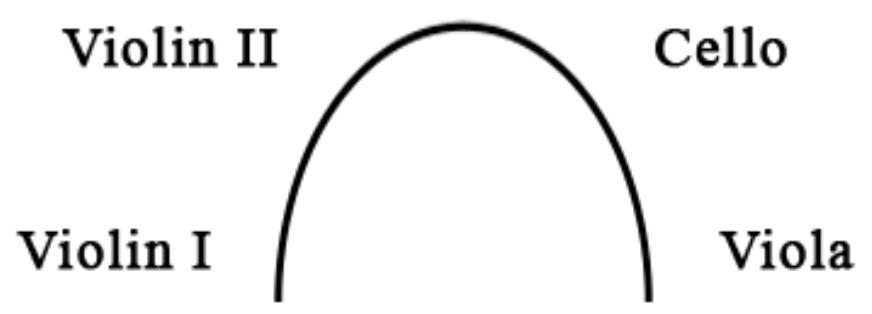

Figure 2.1, Seating Arrangement 1.

This seating is the most common arrangement for the string quartet today. As seen in Figure 2.1 and 2.2, both violins are seated on the left side of the ensemble, the cello is nested in the middle of the ensemble, and the viola is seated on the outer right side. Although this arrangement is not officially called the "traditional" seating, all of the interviewees referred to the seating in this manner.

This arrangement is particularly attractive because the cello is in the middle of the ensemble. The cello facing the audience enables the overtones to project into the audience, creating a fuller quartet sound. However, one disadvantage is that some violists do not like being on the outside of the group due to their f-holes pointing towards the back of the hall. The violist would need to adjust their position in order to have primary material "sounding" outwards. One such potential adjustment is to have the violist's chair slightly angled toward the audience. This would allow the violist to "turn out", the act of the performer to twist their body in order for the viola's f-holes to face closer to the audience. ${ }^{63}$ Another disadvantage with this set up is that the

\footnotetext{
${ }^{63}$ Corinna da Fonseca-Wollheim, "Twisting for Solos, the Violist Is a Quartet's Odd Player Out," New York Times, August 31, 2018, https://www.nytimes.com/2018/08/31/arts/music/string-quartet-viola.html.
} 
inner voices are farther apart, making it slightly more difficult for them to connect. Many groups who choose this arrangement work to overcome these challenges.

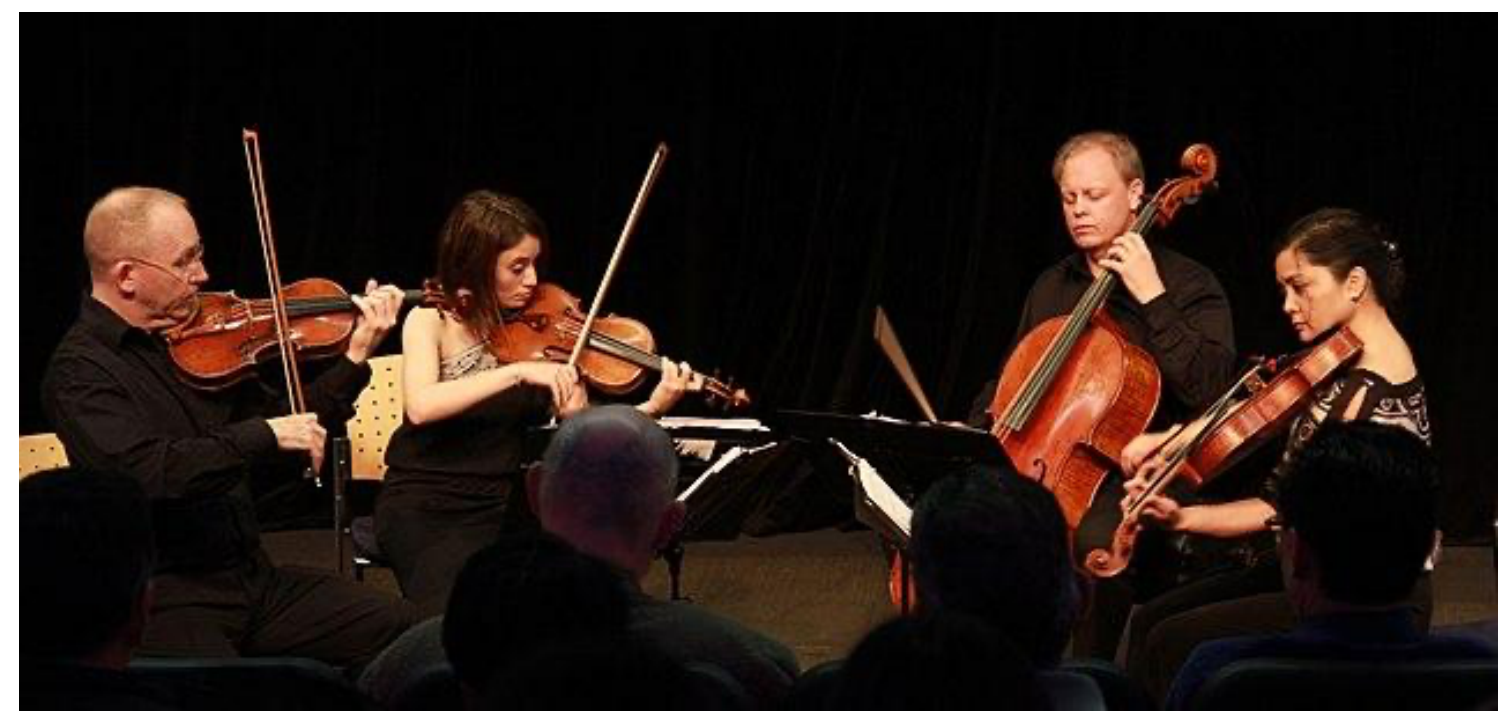

Figure 2.2. Arianna String Quartet. ${ }^{64}$

${ }^{64}$ Princess Ruto, “Arianna String Quartet.” Digital image. https://commons.wikimedia.org/wiki/File:Arianna_String_Quartet_(14193354501).jpg. April 28, 2014. Accessed December 5, 2021. 


\section{Seating Arrangement 2}

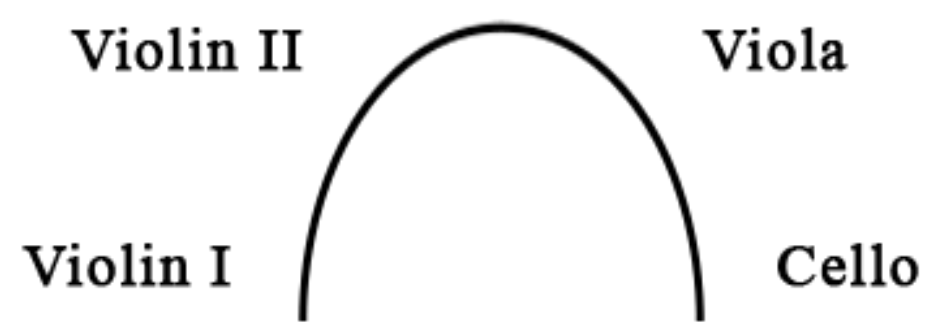

Figure 2.3, Seating Arrangement 2.

Figure 2.3 is another popular option that many string quartets use. The 2021 Fischoff National Chamber Music Competition Gold Medalist and Grand Prize winners, the Risus Quartet, use this seating arrangement. ${ }^{65}$ This set up is often described as the "American" or "Modern" quartet seating. Although the term is rarely seen in publications, it is commonly referred to as such. The attractiveness of this seating is that it allows the inner voices to be seated together and to blend more easily. However, some may suggest the placement of the cello on the outer arc of the quartet results in a lack of core sound from an audience perspective. One remedy may be for the cello to sit with a slight angle to the chair, pointing their f-holes towards the audience. This is similar to the violist's situation in Seating Arrangement 1. Perhaps this is why many violists favor Seating Arrangement 2 since they do not need to "turn out" to project important primary material.

${ }^{65}$ Fischoff, "Congratulations to the Winners," Accessed May 28, 2021. https://www.fischoff.org/news/congratulations-to-the-winners/. 


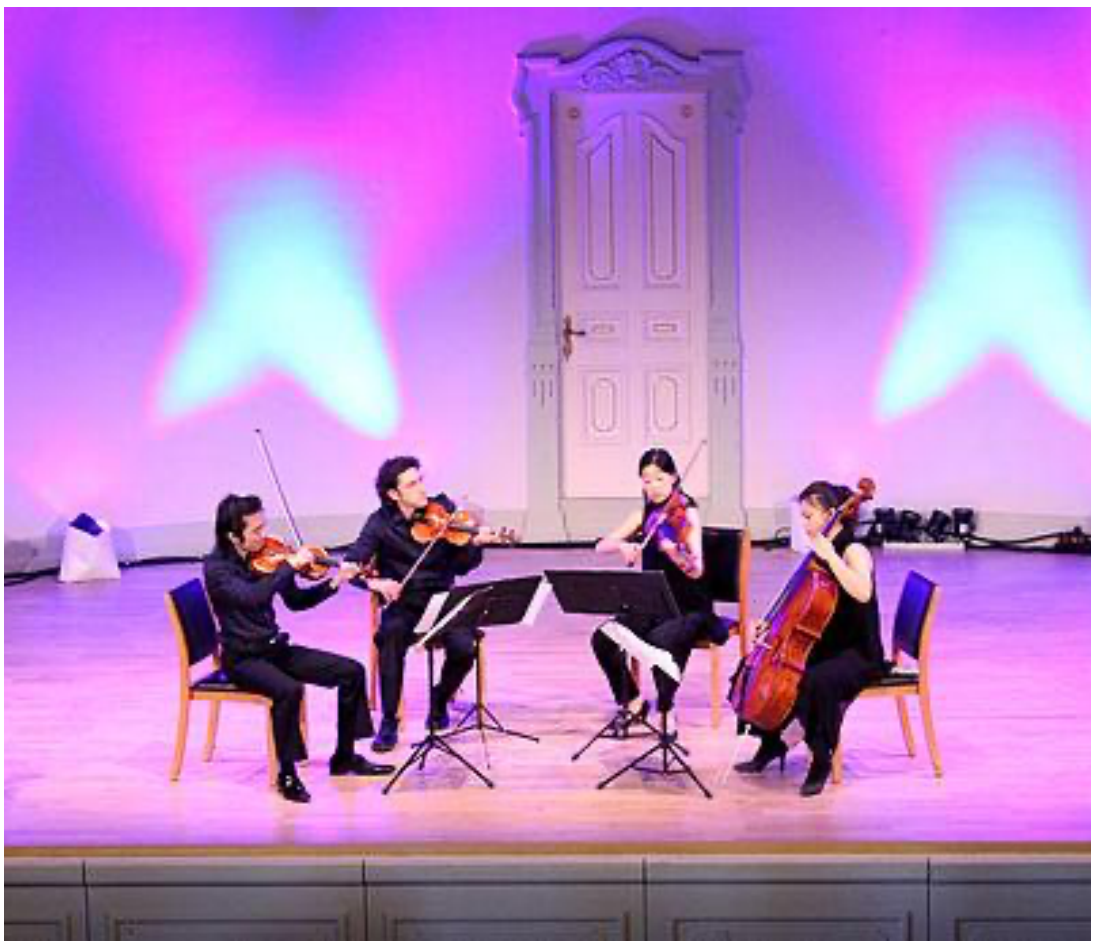

Figure 2.4, Quartet Berlin-Tokyo playing in the Trondheim Chamber Music Festival in $2013 .{ }^{66}$

${ }^{66}$ Kamfest, "TICC 2013 Quartet Berlin-Tokyo.” Digital image.

https://commons.wikimedia.org/wiki/File:TICC_2013_Quartet_Berlin-Tokyo.jpg. September 26, 2013. Accessed December 5, 2021. 


\section{Seating Arrangement 3}

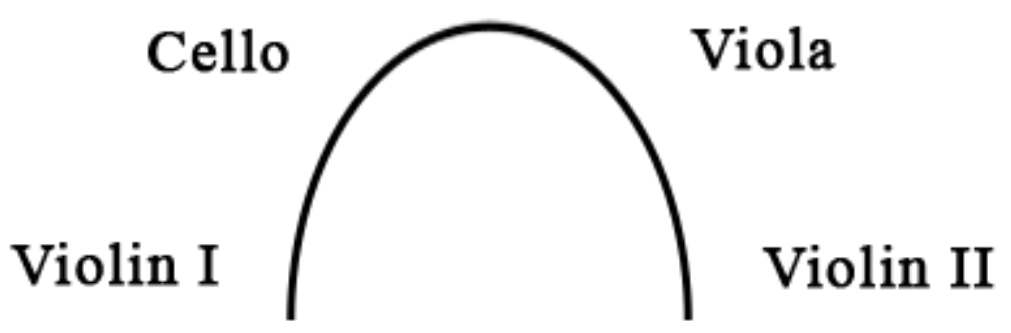

Figure 2.5, Seating Arrangement 3.

This seating arrangement reflects the classic nineteenth-century seating for quartets, which was also favored by Joachim and his quartets (Figure 2.6). ${ }^{67}$ The attractive points are again, the inner voices, viola and violin II, are together. The cello serves as a foundation for the ensemble. One disadvantage of this seating arrangement is that the violins are not seated together. This seating configuration seems to have fallen out of favor and perhaps is the least popular option within current practice.

${ }^{67}$ Standage, 147. 


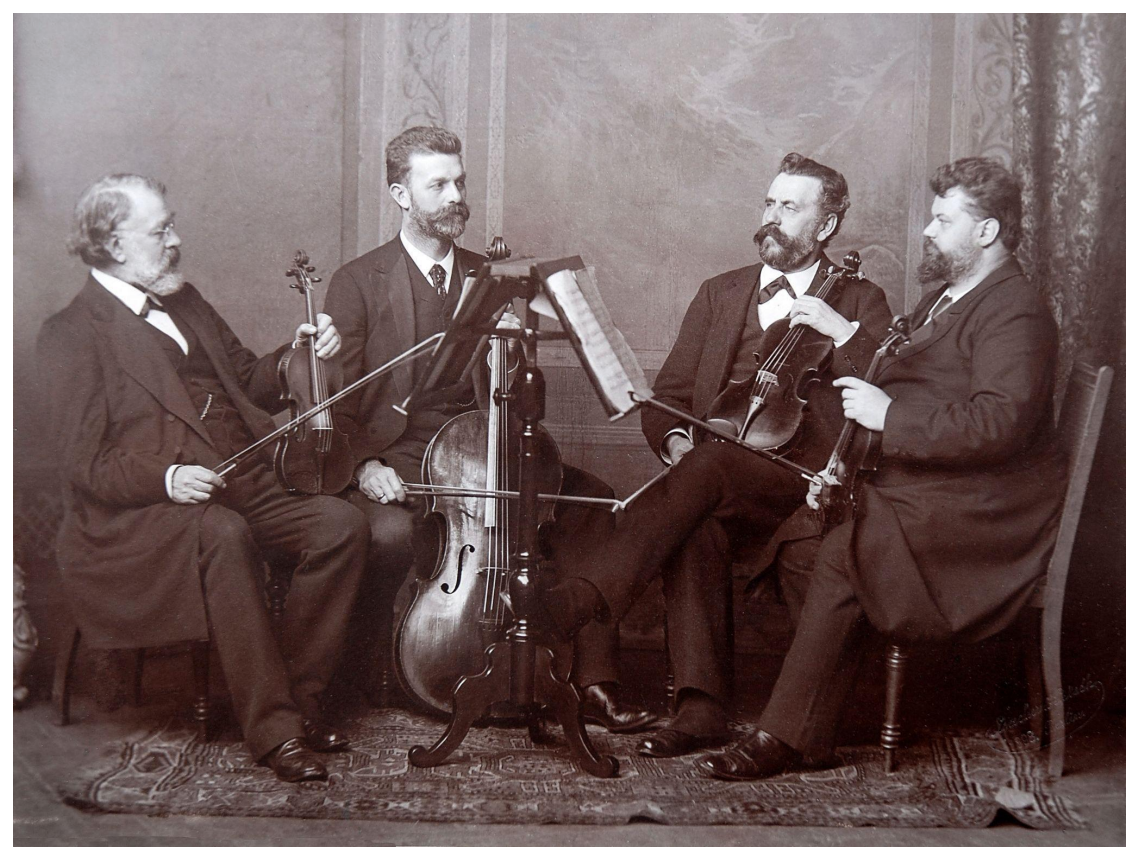

Figure 2.6, Joachim Quartet (1897-1907): (left to right) Joseph Joachim, Robert Hausmann, Emmanuel Wirth, Karel Halír. ${ }^{68}$

68 “The Joachim Quartet, Berlin, 1898.” Digital image. https://josephjoachim.com. August 4, 2014. Accessed May $22,2021$. 


\section{Seating Arrangement 4}

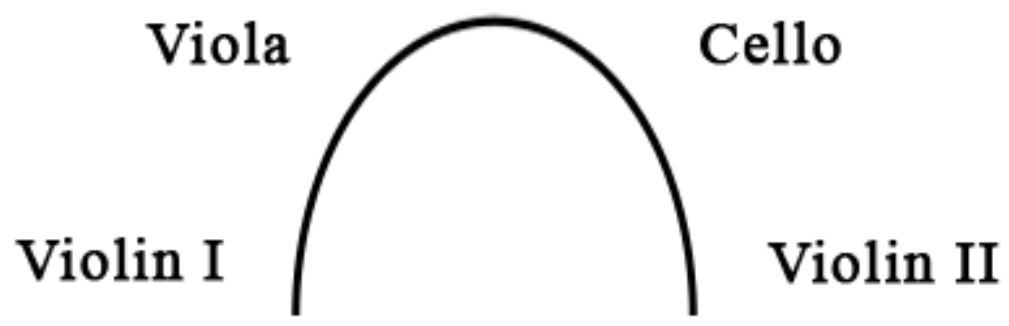

Figure 2.7, Seating Arrangement 4.

This set up is similar to the previous seating arrangement with the antiphonal violins (sitting across from each other). The cello is seated at the center-right of the ensemble, again acting as a foundation, or anchor, for the ensemble's sound to be optimally projected into the audience. The least attractive features of this seating are the separated violins, the separated inner voices (violin II and viola), and the second violin having their f-holes pointed towards the back of the ensemble reducing their overall projection. This has become a less popular choice, similar to Seating Arrangement 3, and had less traction as an option for those spoken to in the interviews. However, Simon Standage writes, "the seating with antiphonal violins has the advantage, both for the violinists themselves and for the audience, of separating the two treble lines and so clarifying the texture." ${ }^{\prime 9}$ As previously stated, this seating arrangement could work very well with a Haydn or Mozart quartet, and it has been a popular choice as a traditional Classical orchestral seating.

Seating arrangements are personal to each quartet, but it is important to note that seating can, and should, be flexible for the needs of the ensemble. Each group should find what works

\footnotetext{
${ }^{69}$ Standage, 146.
} 
best for their own comfort and performance needs. Many ensembles desire a particular sound, and examining different seating arrangements could be a great way to achieve those results. As Mark Rudoff, Ohio State University's Associate Professor of Cello notes, it is not a matter of balance but balances. ${ }^{70}$

\section{Basic Etiquette}

Establishing interpersonal relationships in an ensemble can be as vital as how the music will be performed. In the long run, they can be the structure that maintains the bonds between the ensemble members and can determine the longevity of the group, in some cases. Regardless of the age or experience of an ensemble or its members, it is of utmost importance to provide a beginning framework for how the group members will interact together. Creating an open environment to have a discussion that establishes some rules for group communication and behavior prior to working together fosters positive interactions among members and a sense of teamwork.

David Finckel, the former cellist of the Emerson Quartet, provides a list of rules

for quartet etiquette, "Your Habits and Rehearsal Techniques":

1. Show up on time, or better yet early, for all rehearsals and coachings.

2. Tune up, warm up, and be ready.

3. Learn to tune your instrument quickly, quietly and without making others wait for you.

4. Be ready (think ahead) about what needs to be rehearsed, what might be covered in a rehearsal and in what order. Your colleagues will find you valuable. 5 . Be flexible. Try anything anyone suggests, even if you don't agree. You will be grateful when your group tries your suggestions as well.

6. Make suggestions gracefully. Don't accuse people of slowing down or rushing or playing out of tune if you can phrase it another way ("this passage sounds out of tune" "maybe we could get a more beautiful sound here") and have a practical

\footnotetext{
${ }^{70}$ Mark Rudoff, interview with author, June 2021. (Hereafter "Rudoff interview.”)
} 
suggestion ready for how your wish might be achieved. Don't make suggestions without possible remedies unless you are truly mystified. ${ }^{71}$

\section{Upholding Democracy within the Quartet}

Many professional string quartets, chamber music pedagogues, and coaches describe the string quartet as a democracy. Unlike past practices, the first violin is no longer the designated leader (as found in the pre-1900 string quartet). Evidence of this is found in the practice of early quartets naming themselves after the first violinist, or leader's, name, like the Joachim Quartet. As expressed by the interviewees, this tradition has faded with time and has ushered in the new belief that every member has an equal vote. The philosophy that players need to be open and dedicated to trying others' ideas as if they were their own has become universal. ${ }^{72}$

To encourage this attitude and to maintain a positive environment, Leonard Schranze said that he makes the group put their hand over their hearts and say, "I blame myself" in every first coaching session. ${ }^{73}$ While this can be used as an ice breaker with a new group, it emphasizes the idea that there should never be "finger pointing" time during a rehearsal. Blaming others can only lead to negative interactions within the ensemble which can break down or destroy the openness needed for ensemble members to interact equally and productively.

\section{Preparation before the First Rehearsal}

It is imperative for students to understand the importance of being prepared for every rehearsal. This list of chamber music preparation tips is compiled from the author's experiences:

\footnotetext{
${ }^{71}$ David Finckel, “An Open Letter: Prepare for Your Chamber Coaching,” David Finckel and Wu Han Blog (blog), January 6, 2010, https://artistled.wordpress.com/2010/01/06/students/.

${ }^{72}$ Mark Rudoff, "In Order to Form a More Perfect Union: Enacting a Constitution for a Chamber Group," American String Teachers Journal (November 2000): 72-79.

${ }^{73}$ Leonard Schranze, interview with author, May 2021. (Hereafter "Schranze interview.")
} 
1. Every member should play from the same edition.

2. Every member should have their own copy of the score.

3. The only markings within your part should be bowings, fingerings, and small notes to yourself.

4. Number the measures of the individual part before the first rehearsal.

5. Make sure all of the pages are in good condition. All page turns should be manageable for a cohesive performance.

6. Practice your part before the rehearsal. Ideally each individual part should be prepared to perform up to tempo and with all tempo changes and expressive indications from the score upon the first rehearsal.

7. Do your background research!

a. Where/when was the composer born?

b. Where did they live throughout their life?

c. Who/what were their influences?

d. Where does this work fall within the composer's output, and how does that inform/influence the music?

Susan Waterbury also contributed a tip concerning preparation. She said one of the biggest mistakes before a first rehearsal is to come overprepared with bowings and fingerings. ${ }^{74}$ While it is best to come prepared for a rehearsal, being too prepared in this way can cause a player to be inflexible while working with the rest of the group. First rehearsals mark the beginning of making the artistic and musical decisions within the repertoire. Allowing and trusting oneself to try different bowings and fingerings can result in the faster adjustments needed in order to rehearse a section with the other member's ideas in mind.

\section{Score Study}

Score study provides a way for an individual or quartet to practice or rehearse away from their instrument(s). Using this technique should be proactively practiced by all members of the ensemble. In Waterbury's interview, she mentioned reading through the landscape of the piece before working on the individual part. ${ }^{75}$ This includes listening to the piece, hearing how an

\footnotetext{
${ }^{74}$ Waterbury interview.

${ }^{75}$ Waterbury interview.
} 
individual part works with the other parts, and then beginning to work on the individual part. ${ }^{76}$ She also mentioned the use of an iPad Pro has helped her in her preparation and study of the score because it allows for easy viewing of a score that would normally be either too large or too small to view, and she can control the page turns easily during rehearsals or performances. ${ }^{77}$ Oftentimes, she will read the full score from her iPad in both rehearsal and performance.

Melinda Daetsch, faculty of viola, chamber music, and pedagogy at the Hartt School and the Chair of Chamber Music at the Hartt Community Division, also spoke about her experiences using technology for preparation and score study for chamber music coaching. In 2020, widespread closures due to the COVID-19 pandemic inspired artists to create applications that enabled remote collaboration. ${ }^{78}$ The BandLab application describes itself as "[a] cloud platform where musicians and fans create music, collaborate, and engage with each other across the globe." 79 This app can be used with an Apple or Android device. Each member takes a turn recording their own part and uploading it to a shared project folder. After one instrument records, it is the next member's turn. After practicing along with the previous recording, they record their track, creating a layering process. This cycle continues until all members have recorded their individual part. This layering process is helpful when it comes to score study because of the knowledge each member needs to know in order to correctly perform their part. For example, if all members listen to the cello part alone and discover that the cello holds primary material during measures 1-16, they can better prepare and support the cello's melody. Daetsch said she plans to use this method even after the COVID-19 pandemic is over.

\footnotetext{
${ }^{76}$ Waterbury interview.

77 Waterbury interview.

${ }^{78}$ Melinda Daetsch, interview with author, May 2021. (Hereafter "Daetsch interview.")

${ }^{79}$ BandLab, “About Us,” Accessed June 4, 2021. https://www.bandlab.com/.
} 
Dr. Lauretta Werner, Assistant Professor of Strings at Longwood University, mentioned an important aspect of score study within her interview. She said before every first rehearsal, she studies the score and also looks up the definitions of unfamiliar words. ${ }^{80}$ Understanding the language used in the score can better influence decisions in rehearsals and can lead to more thoughtful performances.

The Cavani String Quartet also addresses basic score study within a handout created by Cotter-Lockard which can be found on their website ${ }^{81}$ The Cavani's basic score study procedures include:

- Finding the tune: always know which voice has the primary materials. This will help the others within the ensemble to understand their role.

- Just because the viola typically has an accompaniment figure does NOT mean to play without inflection or direction.

- Same rhythm "buddies": know who shares the same rhythm as you and who you trade off rhythms with.

- Circle all silences: know where there are silences within the music (grand pauses) and circle those rests in your part.

- Write in rhythmic cues: know where each voice fits. For example, if the second violin is playing half notes, they should know that the viola has continuous eighth notes. This attention to the rhythmic environment enables the performers to better connect and play together.

- Look for places where there is primary melodic material or a subdivided rhythm that can be locked into. ${ }^{82}$

Additionally, for the final bullet point listed above, when indicating or drawing attention to a musical line, it is important to write in the instrument name rather than a colleague's name in your individual part or score. This will prevent confusion later on, especially if the ensemble members change or if the piece is performed with another group in the future (i.e. write "viola," or "vla" rather than "Gabi").

\footnotetext{
${ }^{80}$ Lauretta Werner, interview with author, June 2021. (Hereafter "Werner interview.")

${ }^{81}$ Cotter-Lockard, "The Art of Collaboration."

${ }^{82}$ Cotter-Lockard, "The Art of Collaboration."
} 
The Cavani's add additional advanced score study suggestions that include harmonic analysis, which may not be appropriate for intermediate-level students but could assist their coaches. These more complex aspects could be included at the discretion of the coach or teacher, depending on the ensemble's working knowledge of music theory.

\section{Choosing Repertoire: A Note for Coaches}

Many of the coaches expressed that being a "cheerleader" for certain repertoire is sometimes needed with students. If the piece is not considered flashy enough by the students, they are likely to ask for a different piece or feel unmotivated to prepare and perform the selected piece. However, chamber music education should be similar to that of learning individual instrumental repertoire; there should be a strategic step-by-step flow of chamber music repertoire studied in order for students to gain certain skills. It is important to avoid the lure of pieces that may be too difficult for a student's present level of performance. Fortunately, desirable pieces can be found at every level of learning, with the assistance of a diligent coach. This will ensure students perform pieces that are both educational and interesting, which can be the recipe for success.

\section{Rehearsal Procedures}

\section{Initial Tuning of the Strings}

There are many methods and opinions regarding the tuning of the open strings of a string ensemble. No matter which method is chosen, it is vital to have a consistent procedure as tuning affects the group's overall intonation. Melinda Daetsch mentioned having one coaching session 
as a young student at a summer festival that was spent entirely on tuning the string quartet. ${ }^{83}$ This made a lasting impression on her view of tuning as a sacred event starting every rehearsal.

The Cavani String Quartet provides two methods of tuning the open strings which can be found in Cotter-Lockard's The Art of Collaboration:

Method 1:

1. The cello gets the A from a tuner.

2. Everyone else gets the A from the cello.

Method 2:

1. Everyone tunes each of their strings to a tuner.

2. Performers ensure that the tuners are on the same settings.

i. $(440 \mathrm{~Hz}$ vs. $441 \mathrm{~Hz}$, equal temperament vs. just temperament)

3. Performers always tune one-by-one. (No orchestral-style tuning!)

i. Performers always test open strings together after everyone has had a chance to tune. ${ }^{84}$

Susan Waterbury suggested two tuning procedures depending on the repertoire performed. ${ }^{85}$ Her first method was similar to Method 2 from the Cavani String Quartet's tuning procedure. For music written with many open strings, it is helpful to tune each individual string with a tuner. With the second tuning procedure, Waterbury mentioned tuning in perfect fifths. This would be a better option for music not written with frequent open strings since the cello and viola's C strings can sound out of tune with the violins' E strings.

Dr. Erin Ellis, Assistant Professor of Cello at West Virginia University, suggests tuning string by string. ${ }^{86}$ This is similar to the Cavani String Quartet tuning procedure, but differs in that this method allows each member of the group to tune together. Having the group tune string by string allows members to trust each other and supports constructive criticism such as, "I think your G string is a little flat. Let's compare them together.” Dr. Ellis also suggests tuning

\footnotetext{
${ }^{83}$ Daetsch interview.

${ }^{84}$ Cotter-Lockard, "The Art of Collaboration".

${ }^{85}$ Waterbury interview.

${ }^{86}$ Ellis interview.
} 
individually instead of orchestral-style tuning. This is a great procedure for both beginning and intermediate groups because it allows for careful tuning and added focus on the members' tuning. Students tend to rush through orchestral-style tuning and do not listen as carefully as they should. This is an unfortunate culture that can develop in the classroom and orchestra settings, perhaps due to lack of time.

Mark Rudoff shared his tuning procedure which was taught to him by violinist Renato Bonacini. ${ }^{87}$ Normally, the thought process behind using the A string as the center of tuning is that the violins only have to tune up one fifth. In a quartet setting, Rudoff suggests tuning to the D string. This way all players have a central tuning pitch from which they have two fifths to tune, either higher or lower, as opposed to half the ensemble having one fifth to tune and the other half having three. Rudoff's tuning procedure:

1. The cello tunes their $\mathrm{D}$ string and tunes their instrument.

2. The cello shares the D to the viola, second violin, and first violin, separately.

3. The cello will test their $\mathrm{C}$ string against the violins' $\mathrm{E}$ string.

4. The cello and viola will match their $\mathrm{C}$ strings. ${ }^{88}$

\section{The First Rehearsal or Coaching}

If the students have not met prior to their first coaching session, it is a good idea to get them acquainted with each other through various ice breakers. Daetsch mentions that she has each member of the group play something on their instrument. ${ }^{89}$ This can range from a solo piece they know, an improvisation, or any type of sound that expresses

\footnotetext{
${ }^{87}$ Rudoff interview.

${ }^{88}$ Rudoff interview.

${ }^{89}$ Daetsch interview.
} 
who they are as an individual. This enables the group to be creative and feel relaxed after their first meeting in order to begin rehearsing in a safe space.

Dr. Ellis suggests asking a member of the group where they are from and to supplement with another non-musical question such as, "When we are done with the scale warm-up, tell me what the capital of Oklahoma is." ${ }^{90}$ This can take the pressure off the student because there is a definite answer. This is a fun way to encourage rehearsal/coaching protocol, and also helps to build trust between the coach, the student, and the group.

\section{Ensemble Communication During Rehearsal}

As a group encounters conflict and musical problems, the issue of ensemble communication during rehearsal becomes central. This is where the honeymoon stage ends and ideas previously mentioned, such as Basic Etiquette and Upholding Democracy within the Quartet, are put to the test. The close-working nature of a group, which can include rehearsing together for multiple hours at a time, can be easily influenced (for better or for worse) by individual members' attitudes and dispositions. A member's negative attitude can easily affect the success/tone of the rehearsal. Individuals should commit to coming to rehearsals with a good attitude, regardless of what is happening outside of rehearsal. As Rudoff writes in his article, "Nobody has the right to bear arms. Verbal artillery must be checked at the door."91

It is human nature for one to feel vulnerable or defensive when approached with criticism. Therefore, it is important for everyone to use the Golden Rule: "do unto others as you would have them do unto you." Suggestions and criticisms should be specific and

\footnotetext{
${ }^{90}$ Ellis interview.

Ellis originally had a math equation, but for the purpose of this document the author chose a state capitol question for easier reading comprehension.

${ }^{91}$ Rudoff, 76.
} 
constructive. David Finckel writes, 'Be encouraging and sensitive: 'This sounds awful!' is nowhere near as helpful as 'This could sound much better!",92 Without proper guidance well-intended feedback can be received with frustration, becoming a negative experience for all involved.

Sometimes in a rehearsal a group can come to a deadlock over a decision or during a discussion. The goal of the ensemble may be to always finish their work on each section before leaving it. However, that may not always be the best idea. Rudoff writes, "If you have tried everything and further discussion is only going to make things worse, table the issue and move on to new business." 93 It is best to know when not to pursue a section in rehearsal. This will keep all members in a less frustrated headspace.

\section{General Rehearsal Procedures}

When a quartet gets past their first meeting, general rehearsal procedures become a foundation of how the group will work productively. It is important to establish procedures from the beginning. The following information concerns possible rehearsal procedures and techniques.

Starting a working rehearsal can be difficult, especially with a new group. Many of the teaching quartets, such as the Cavani String Quartet and the Miró Quartet, suggest opening each rehearsal with playing before speaking. ${ }^{94}$ After a few minutes of playing, one method to start the rehearsal is to have each member pick one spot that they would like to fix or improve, the catch being members are given a predetermined amount of time to complete this task. Dr. Molly Gebrian, Assistant Professor of Viola at the University of Arizona, suggests using an interval

\footnotetext{
${ }^{92}$ Finckel, "An Open Letter: Prepare for Your Chamber Coaching."

${ }^{93}$ Mark Rudoff, 76.

${ }^{94}$ Miró Quartet, "Musical Hourglass,” 1999. Handout.
} 
timer. ${ }^{95}$ An interval timer allows you to set an alarm to go off every $\mathrm{X}$ number of minutes. There is a free app for iPhone and Android called "Interval Timer" that can be found in the Apple App Store or Google Play Store. ${ }^{96}$ Having a predetermined amount of time helps the group avoid becoming stuck on one spot or idea for too long during rehearsal and keeps the rehearsal moving. It makes sense that allowing only five to ten minutes on a section also encourages the group to problem-solve quickly rather than at a leisurely pace.

An ensemble can also get into a rut by going over the same material at every rehearsal. Mark Rudoff calls this the "Groundhog Day Rehearsal." $" 97$ To avoid this phenomenon, it is important for the ensemble to plan before and at the end of every rehearsal. Each member needs to contribute to this plan. This process can be as simple as, "For tomorrow's rehearsal, I would like to go over the fugue section from rehearsal letters G-H.” Even a directive this basic can provide more focus and productivity in the next rehearsal. Another way of avoiding a "Groundhog Day Rehearsal" is to record and listen back to the recording while making a specific list of items that are needed to be fixed within the next rehearsal. This level of work is needed for pre-performance or pre-competition preparation.

An ensemble should record themselves at least once a week. Recording is the truth-teller of what is going well and what needs more work. While run-throughs of pieces are vital, it is equally important to record smaller sections. One suggestion is to listen back to the recording at $.75 \mathrm{x}$ speed. This playback speed is fast enough to not "zone out" while listening but slow enough for everyone to understand what is not working well in the section.

\footnotetext{
${ }^{95}$ Molly Gebrian, "Interleaved Practice: The Best Practice Method for Reliable Performance," Journal of the American Viola Society 32, no. 2 (Fall 2016): 40.

${ }^{96}$ Gebrian, "Interleaved Practice."

${ }^{97}$ Heather K. Scott, "5 Ways to Make the Most Out of Your Rehearsal Time," Strings 26, no. 6 (January 2021): 35. Groundhog Day (1993) is a film made starring Bill Murray. A man relives the same day over and over again when visiting the small town of Punxsutawney to film a report about their annual Groundhog Day.
} 
In an interview with String Magazine, the Dover Quartet discussed their rehearsal techniques leading up to a big competition round. ${ }^{98}$ These procedures can easily be adopted for pre-performance or pre-competition rehearsals. The quartet stated that they play through their repertoire, and at the end of each movement, members take time to write down specifically where any issues occurred and exactly what happened. After the run-through, each individual would show their list to the other members, and often to their surprise, they would have similar lists of problem spots within the repertoire. This practice would be particularly beneficial for a growing ensemble because it would establish trust and provide a working rehearsal procedure.

\section{Making Interpretive Musical Decisions as an Ensemble}

Making musical decisions as an ensemble is a core task during rehearsals. Every member of a group will certainly have opinions and ideas about the music. The aim of an ensemble is to combine those ideas and come to a singular vision for a performance.

The first step of finding these opinions and ideas is within each individual group member's preparation. Group members should find audio or video recordings of the piece they have chosen to play, listen to them, and share their favorites with the group. Not only does this help each individual in their initial preparation, but it also establishes possible performance intentions and inspirations and promotes communication between group members. It is best for the ensemble members to listen to several recordings of the chosen piece to expose them to a variety of interpretations and ideas. The group, however, should take care not to simply mimic another quartet's performance, but rather create their own individuality and explore their own musicality within a performance. ${ }^{99}$ One of the first ways members can begin to share their ideas

\footnotetext{
${ }^{98}$ Miranda Wilson, “The Dover Quartet Offers 8 Career Tips to Aspiring Chamber Ensembles," Strings Magazine, September 2015. https://www.doverquartet.com/features/2015/8/28/strings-magazine.

${ }^{99}$ Loft, Ensemble!: A Rehearsal Guide to Thirty Great Works of Chamber Music, 17.
} 
from the recordings they have studied is to share the metronome markings from their preferred recordings. The proposed tempo goals may differ among group members, but they are worth discussing and comparing with the indications in the score.

As musical ideas are offered and attempted in an ensemble, members must understand that every plan can change. They should look at the beginning of learning a piece like an artist's sketch. With the imagery of the artist's sketch, students understand that they can erase lines, create darker lines, and even get a new piece of paper. ${ }^{100}$ This teaches them that they must look at the whole rather than the minute. If you look at the minute you may get too much into the details and miss the bigger picture. Knowing and understanding that a single decision is never completely unchangeable can free a group to be more creative and maintain positivity.

Learning basic chamber music fundamentals are crucial to every chamber musician's education. If these fundamentals and guiding principles are done well, they can lead to positive experiences for all involved, ultimately nurturing continuing growth as a chamber musician. Mastering these skills creates chamber musicians who can work together and thrive.

${ }^{100}$ Rudoff interview. 


\section{Chapter 4}

Chamber Music Rehearsal Techniques

This chapter will offer a variety of practical approaches and techniques for learning and rehearsing repertoire. A "rehearsal technique" is a specific practice or exercise taught to a group by a coach for use in rehearsals to improve their performance. ${ }^{101}$ Students should be able to learn these techniques and apply them to their chamber music rehearsals outside of coaching sessions. This concept is similar to the relationship between what is taught in private lessons and then applied in individual practice sessions.

Dorianne Cotter-Lockard's dissertation “Chamber Music Coaching Strategies and Rehearsal Techniques that Enable Collaboration" has an entire chapter devoted to rehearsal techniques that the Cavani String Quartet utilizes while teaching and coaching student string quartets. ${ }^{102}$ These rehearsal techniques could seemingly benefit students of all ages and abilities, and would be very appropriate for those at an intermediate-level.

This chapter will address the challenges that all inexperienced chamber music ensembles face that came to the forefront during the research stage of this project. These problem areas are intonation, ensemble and coordination, group rhythm and pulse, cueing, and musical expression. For each subject, rehearsal techniques specific to that topic will be listed and described, however, many of these exercises can be intertwined together for even more beneficial results. These techniques and exercises are not intended to be a comprehensive list but rather a starting point to aid in rehearsals and coachings. Using them can develop the musical and technical skills needed to perform repertoire for an ensemble's current playing level and beyond.

\footnotetext{
${ }^{101}$ Dorianne Cotter-Lockard, "Chamber Music Coaching Strategies and Rehearsal Techniques that Enable Collaboration," PhD diss., (Fielding Graduate University, 2012).

${ }^{102}$ Cotter-Lockard, 89-110.
} 


\section{Intonation}

Intonation is a cornerstone of music-making. When first forming an ensemble, individual members may have their own sense of intonation, therefore group intonation must be learned together. Mark Rudoff suggests spending at least 10 minutes of every hour in rehearsal on intonation. ${ }^{103}$ Creating time to work on group intonation consistently can produce impressive results. This work can impact the sound and tone of the group and raise the level of every performance.

Scales

Many instrumentalists focus on scales during their individual practice, but chamber groups can easily implement scales into their daily warm-up routine. While playing scales as an ensemble, they can learn much more than intonation. This is also an opportunity to match articulation, to match bow speed, and to learn physical movements such as cueing.

Leonard Schranze said every group member should take turns leading the scale practice, guiding the timing, volume, and intonation. ${ }^{104}$ The range of an octave is most effective with this rehearsal technique. The leading ensemble member should be twice as loud as everyone else to rehearse balance. If the higher instruments (typically violins) are too loud, the sound can become distorted, unbalanced, and out of tune. Playing without vibrato can be highly effective in this exercise because vibrato can also distort the true pitch.

\footnotetext{
${ }^{103}$ Rudoff interview.

104 Schranze interview.
} 


\section{Variation: Round}

This practice focuses on flexibility of the performer's ear and how they learn to quickly adjust, an essential skill in playing chamber music. Designate a person in the ensemble to begin with a scale. When the first performer reaches the third note, another member should begin the scale, starting on the first note of the scale. The process should continue until every member is playing. Once each member arrives at the end of the scale, they should sustain the tonic, or starting, pitch.

\section{Variation: Hocket Scale}

The hocket scale is a vehicle for practicing cueing, matching articulations, and building group visual communication (eye contact). Designate one person out of the group to begin the scale. ${ }^{105}$ Dr. Erin Ellis suggests the quarter note should equal $80 \mathrm{bpm}$. The scale will consist of four eighth notes per note of the scale (D-D-D-D, E-E-E-E, etc.). Again, one octave is enough as it is easily digestible for younger students. By the time the initiating person gets to their second note, they must prepare to cue the next member in, who will play the following two notes of the scale. The order can go from the initiating person's left or right. Similarly, they must cue in the next person to complete their turn. This continues until the scale is complete.

\section{Hitting the Brakes}

If a group is having issues agreeing on pitch within a section, have them play the section at their desired tempo. When they arrive at the pitch in question, have the group hold the pitch. This will allow time to adjust and understand what they need to do for their next try.

\footnotetext{
105 Ellis interview.
} 


\section{Half-Speed}

Have the group play at half tempo (regardless of how "slow") to help identify where the intonation issues arise. ${ }^{106}$ Slowing down a passage allows the quartet to focus on intonation both vertically and horizontally. While working on vertical tuning, the quartet focuses on the intonation chord by chord. Horizontal tuning focuses on the movement of harmonic progressions within a section. Through the process of horizontal tuning, the quartet targets their tuning by intervals, chord progressions, and ultimately, listening to the larger phrase.

\section{No Vibrato}

Rehearsing without vibrato allows the group to focus on intonation. This is due to the fact that the pitch can be heard without the micro-changes in pitch which vibrato produces. Playing without vibrato exposes intonation issues and helps to uncover which specific pitches need attention. $^{107}$

\section{Four-Part Chorales}

Melinda Daetsch has all her chamber groups (beginner, intermediate, and advanced) play four-part Chorales by J.S. Bach. ${ }^{108}$ While an ensemble does not need to use Bach Chorales specifically, they are a starting point. High school orchestra director and author Dr. Christopher Selby offers many options in his online handout, Habits of a Successful School Orchestra, and his book, Habits of a Successful Orchestra Director. ${ }^{109}$ An example of a chorale Selby provides

\footnotetext{
106 Waterbury interview.

107 Cotter-Lockard, 101.

${ }^{108}$ Melinda Daetsch, email to author, June 7, 2021.

David M. Bynong, "24 Chorale Harmonizations by J.S. Bach: Transcribed for String Quartet," American Viola Society, 2016. http://www.americanviolasociety.org/PDFs/Resources/Scores/Bach\%2024\%20Chorales.pdf.

${ }^{109}$ Christopher R. Selby, "Habits of a Successful School Orchestra - Giamusic.com." GIA Publisher, Inc. Accessed November 1, 2021. https:/www.giamusic.com/pdf/8628HO1-Strings.pdf.

Christopher R. Selby, Habits of a Successful Orchestra Director (Chicago: GIA Publisher Inc., 2016).
} 
is the Pavane from Peter Warlock's Capriol Suite. Additionally, Frank Spinosa and Harold W. Rusch's book, Fine Tuning: 50 Intermediate String Ensembles for Developing Solid Intonation and Tone Production, has chorales and short pieces organized by key (major and relative minor) which appear in order of difficulty. ${ }^{110}$ This collection features works representing the late Renaissance period through the early Contemporary period. Chorales are excellent for ear training, and intonation practice, especially for new groups. Besides working on issues involving intonation, chorales also provide practice for cueing and ensemble sound.

\section{$\underline{\text { II. Ensemble and Coordination }}$}

Most coaching and rehearsal time is spent on ensemble work, or as the word "ensemble" translates from French, coordinating the members to play "together" as a unit, therefore it is important to have many strategies and exercises to improve ensemble playing. The following topics within this section are: ensemble work, listening, and articulations.

Coordination in an ensemble is both an individual and a group activity. Within an individual's practice, students learn scales, etudes, and other exercises within their repertoire in order to practice their coordination. However, it is a different experience with a string quartet because the four members must coordinate within the group rather than just one person alone. To achieve this, one aspect each member needs to understand is their role, as well as the tendencies of the other instruments in order to perform in sync. For example, one such tendency is that the cello speaks slower than the violin and the viola. Andre Roy's String Quartet Technique

\footnotetext{
${ }^{110}$ Frank Spinosa and Harold W. Rusch, Fine Tuning: 50 Intermediate String Ensembles for Developing Solid Intonation and Tone Production (San Diego: Neil A. Kjos Music Company, 1989).
} 
responds to these tendencies and offers what he calls his Coordination Exercises to "enhance the quartet members' abilities to respond to one another with the greatest of precision."111

Another important element of playing together precisely is listening to each ensemble member. While this seems to be an obvious statement, the act of listening while playing an instrument can be very difficult, requiring constant practice and attention. ${ }^{12}$ Learning to listen helps a member discern what they need to do to support their group members in the musicmaking. Listening is crucial for ensemble unification of many aspects, such as, the balance of each instrument's volume within the quartet, the matching of bow articulations, and the ability to imitate another player's musical ideas.

When it comes to string quartet playing, finding the desired articulation and note length that most effectively conveys the music or the wishes of the group can be difficult. As previously stated, the cello speaks slower than the rest of the quartet due to string size giving it a different "speaking" time compared to the violins or viola. There is a need for a unified approach to bowing to truly play together. In addition, shorter bow strokes are more difficult for intermediate-level students as they are continuing to develop staccato and especially spiccato bow strokes.

\section{Ball of Sound}

Ball of Sound, also known as Play to the Middle, is a concept that comes from the Cleveland String Quartet. This concept is used to increase nonverbal communication and blending of the sounds of the individual members, thus developing a group sound. For this exercise, every member should play "towards" the middle of the group, imagining all members

\footnotetext{
${ }^{111}$ Roy, 5.

${ }^{112}$ Rudoff interview.
} 
are feeding a ball of sound. For a younger group, placing a stuffed animal in the center can help in the understanding of where their sound needs to be placed. ${ }^{113}$

\section{Smelling Range}

Another suggestion is to have the ensemble remove the music stands, sit very close to one another, and play from memory. ${ }^{114}$ This allows the ensemble members to give their full attention to the group (rather than their own individual part). This close seating arrangement was taught to me by Leonard Schranze.

\section{Take a Stand}

When a quartet member has the melody or primary material, they should stand up from their chair (cello is the exception, but they can employ a different body gesture such as a higher head level). Many groups, especially younger ones, enjoy this exercise because it involves physical activity. This is very exciting when the group has a quick passing of melodic material throughout the ensemble in a small number of measures. This is similar to the Cavani String Quartet's technique, Shine the Light.

\section{Shine the Light}

Quartet members imagine they are shining the light on the person playing the primary theme. ${ }^{115}$ The accompaniment is not considered "background," but rather their role is to shine a light on the melody to inspire and support. Shine the Light can be used for two practical purposes: a physical gesture to practice physical communication and incorporating a

\footnotetext{
${ }^{113}$ Cotter-Lockard, 93.

${ }^{114}$ Schranze interview.

${ }^{115}$ Cotter-Lockard, 100.
} 
choreography that increases the understanding of every member's role. Variation: Imagine passing a cup of tea around to each quartet member as they take a turn in the spotlight. ${ }^{116}$ With the image of passing a cup of tea around the ensemble, this allows the members to focus their sound and attention to the person needing the spotlight.

\section{Left Hands Alone}

"You must eat up one another's left hands" - The Budapest String Quartet 117

This exercise is to rehearse or "play" the music without the players' bows. There are many ways in which this technique can be presented and performed during a coaching or rehearsal. First, the ensemble can pick one person's left hand to watch and follow as the group plays. Another option is to look at the person's left hand to your left or your right. The technique will only work if everyone leads with the same musical energy and character. This technique has been a staple of the Cavani String Quartet's rehearsals and coachings.

\section{Spreading Out the Ensemble}

Each person sits or stands in a corner of the room and plays while directing their sound, intention, and energy across the room to their colleagues. The Cavani String Quartet calls this Four Corners of the Room. ${ }^{118}$ Variation: Have the violins and viola stand in the corners of the room and walk toward the cellist. Then the group should face away from one another and play a passage with their backs towards one another. Variation: Remove the music stands or turn off the

\footnotetext{
116 Cotter-Lockard, "The Art of Collaboration."

117 Cotter-Lockard, "The Art of Collaboration."

118 Cotter-Lockard, 103.
} 
lights and play from memory. ${ }^{119}$ These exercises encourage listening by changing the performing conditions in an atypical way requiring the performers to "open" their ears.

\section{Strategic Listening}

Pick a member of the ensemble to lead the performance of a passage. All members play along with the chosen leader and mirror whatever changes in the tempo, dynamics, or other elements in the music they demonstrate as closely as possible. Variation: listen to the person to your right. This exercise helps with flexibility and strengthens listening across the ensemble.

\section{Switching Seats}

Sit in a different seat than is normal within the quartet configuration. For example, the cellist sits in the second violinist's seat, the second violinist sits in the violist's seat, etc. This allows the group to experience a different way of listening within the ensemble. Oftentimes members within the ensemble discover new things to listen to just by sitting in a different position in the group.

\section{Look Up Every Bar}

All members are required to look up and out of their parts at least once per bar. ${ }^{120}$ Not only does this help with group visual communication, but also helps with initiating cues. By looking up every bar, members are able to quickly respond to gestures.

\footnotetext{
${ }^{119}$ Daetsch interview.

${ }^{120}$ Cotter-Lockard, "The Art of Collaboration".
} 


\section{Layering It}

This is particularly good for staccato sections. Designate a leader for this exercise. This might be suited best for the cello to lead for the first two rounds due to its natural delay in sounding. On a single repeated pitch, the first person will play the staccato note length that they choose or prefer to hear in the music. Then, add in another person to match the bow stroke of the first person. If the articulations are not matching, the quartet members who are not playing can help to verbally describe how the notes and bows need to change to match. The description can include the sound, or consonant, of the front, middle, and end of the note. Once the articulations are matching, add the third and fourth person one at a time until the sound is unified. Once this is accomplished, start this exercise again but with a newly designated leader. Typically, the members will naturally evolve their stroke into something that is matching. ${ }^{121}$

\section{Pizzicato instead of Arco}

The Cavani String Quartet offered a free online program, Virtual Intensive Quartet Seminars, during the 2020-2021 academic year. They held coachings for student quartets at the top conservatories in the United States. One of the guest coaches, Peter Salaff, a founding member of the Cleveland String Quartet, made an interesting suggestion for the young quartet to help them to match an articulation. The viola and cello had a supportive role while the violins had the melody. Interestingly, Mr. Salaff suggested having the violist play their part while using pizzicato instead of the bow. Instantly this created a different character and sound that fit the quartet's interpretation better. After finding the correct length and sound using pizzicato, the violist then played with the bow.

\footnotetext{
${ }^{121}$ Schranze interview.
} 


\section{Group Rhythm and Pulse}

As teachers, we often see students rushing through rests or not fully counting a longerduration note such as a whole note. It is possible that some students may not yet have developed a strong sense of rhythm and pulse. A group's rhythm and pulse enables the members to understand how to perform in time together, which can be difficult if students are at different skill levels. The following exercises and rehearsal techniques will help to unify and solidify a group's rhythm and pulse.

\section{Group Rhythm and Pulse with the Metronome}

\section{Changing the Metronome's Pulse}

Begin with the metronome sounding a subdivision of eighth notes. ${ }^{122}$ Once the group is comfortable with hearing eighth note subdivisions as they play, change the pulse on the metronome to quarter notes, then half notes, once per bar, once every two bars, and once every four bars. It is essential for a group to understand exactly which pulse problems might exist in their performance and to find where they are occurring. This activity can help a group to do just that. For example, they can discover "We are slowing down between beats 1 and 2," Then the group can note this in the music and make a mark in their scores to help them avoid the mistake in the future.

\footnotetext{
${ }^{122}$ Rudoff interview.
} 


\section{Off Beats}

Another technique that solidifies group pulse is to shift what is normally played on the beat to the off beat. Not only does this make a section more secure, but it deepens the understanding of how the individual parts fit together.

\section{Group Rhythm and Pulse without the Metronome}

One Note

For pieces heavily dependent on rhythmic alignment, simplify a passage by having each player play the rhythm of their part by using a singular, repeated note. This allows for the group to focus on the rhythm and articulation rather than the pitches.

\section{Short Articulation}

Taking a short section of a movement or piece, play the section using pizzicato. Only hearing the "front" of the note will help students become aware if they are not lining up as a group. Variation: use this technique while substituting a short articulation such as staccato or spiccato (depending on the skill level of the ensemble).

\section{Chamber Music Aerobics}

Chamber Music Aerobics is one of the Cavani String Quartet's most famous rehearsal techniques. ${ }^{123}$ While playing a scale or passage of music, the quartet will move together from the waist from right to left, and later, up and down and forward and backward, in a steady pulse. This technique is especially effective for slow movements. It creates a setting where pulse can be found in physical movement.

\footnotetext{
${ }^{123}$ Cotter-Lockard, "The Art of Collaboration".
} 
The next step would be to use these body motions, but only on downbeats. To make this more challenging, try the motion on a "weaker beat." For example, if the music is in $4 / 4$, the body movement would occur on either beat two or four. This exercise is excellent for group pulse, team building, and group communication. It could also be used during a warm-up activity, like group scales, to prepare the body and mind of the ensemble.

\section{Marching}

Another option for group pulse is to march. This can be done while standing or seated. With the desired tempo, every member will pick up each foot off the ground and then that foot will impact the floor on the beat. This does not mean only tapping of the toes. The whole foot must come off the ground and into the air. This helps to internalize the tempo, as well as to notice if there is a fluctuation of tempo.

\section{Variation: Walking}

Many coaches discussed having their chamber groups walking around the room while singing or playing their parts. For best results, the players should be committed to walking in the character of the music. Again, adding physical movements can influence and build upon a student's inner pulse.

\section{Human Metronome}

Designate one person in the ensemble to be a metronome, whether that is counting out loud, clapping, or conducting. ${ }^{124}$ This is beneficial for a section that requires a ritardando or

\footnotetext{
${ }^{124}$ Daetsch interview.
} 
accelerando. Next, have each individual group member be a human metronome to see which pulse feels the best to create an organic slowdown or speedup.

\section{Clapping}

Quartet members clap the rhythm of their parts together. This must be done with the same dynamics as printed in their parts. This is particularly good for understanding how each part fits rhythmically and musically within the other members' parts.

\section{Conducting}

All ensemble members conduct a section together. Each member needs to conduct in the same character and style as the piece they are playing. ${ }^{125}$ Conducting also reveals individual pulse issues and can quickly fix problems within an individual part and in the group. The group can also count aloud when there is a rest or count throughout the conducting to solidify the group pulse. Afterward, each member may take a turn to lead the ensemble by conducting their interpretation of the section.

\section{Shakespearean Counting}

\section{"Be a Shakespearean actor!" 126}

Without instruments, count all parts aloud as a group following the music's character, phrasing, and dynamics. ${ }^{127}$ Ensure the style and vocal inflection represents the composer's musical intent. This encourages students to internalize rhythm, dynamics, and how each part "fits" with one another. Variations: Try counting in the language of the composer. ${ }^{128}$ Stand up

\footnotetext{
${ }^{125}$ Daetsch interview.

${ }^{126}$ Cotter-Lockard, "The Art of Collaboration."

127 Cotter-Lockard, "The Art of Collaboration."

${ }^{128}$ Cotter-Lockard, "The Art of Collaboration."
} 
and count parts in character, using hand gestures as if having a conversation. A next step would be to count only the odd beats, count only the even beats, and to get even more creative, count only on the "ands" of the beats. Shakespearean Counting is another Cavani String Quartet rehearsal technique.

\section{Cueing}

Cueing is an integral part of performing in any ensemble - large or small. A cue is "[a] direction to enable a singer or player to come in at the right time." ${ }^{129}$ A cue can be used as a direction in addition to the signal to start a piece or section. The Cavani String Quartet suggests not using the words "leader" or "follower." 130 The word "follower" tends to sound passive, which is not conducive to the reality that the non-melodic parts are just as important as the melodic material. ${ }^{131}$ The word the Cavani's use for "leader" is "initiator," and the rest of the group must be proactive and also initiate for the cue to be accurate. ${ }^{132}$ Additionally, one could think of the cue as a physical motion that also adds to the visual aspect of the musical performance.

\section{Basic Cue}

The basic cue is an essential part of chamber music. In the beginning, students of arm instruments, like violins and violas, have issues with learning how to cue. Typically, they will only go up with their cue. However, in order to have a successful cue, they need to come down

\footnotetext{
129 "Cue, n.2". OED Online. September 2021. Oxford University Press. https://www-oedcom.wvu.idm.oclc.org/view/Entry/45574?rskey=Hbwfew\&result=2\&isAdvanced=false (accessed November 20, 2021).

${ }^{130}$ Waterbury interview.

${ }^{131}$ Cotter-Lockard, 85.

${ }^{132}$ Cotter-Lockard, 85.
} 
with their instrument (pre-cue) and then up (cue), and then back down to mark where to play. The up and down gesture of the violin or viola creates a movement that makes the other members of the ensemble aware of tempo, character, and note placement. Additionally, Waterbury suggests that the gesture of the cue is smaller when the tempo is fast and bigger with a slower tempo. ${ }^{133}$ Most importantly, an inviting cue is most likely to be a successful cue.

An inviting cue is one in which the initiator has eye contact with the members of the group before beginning the cue. Without eye contact, the cue comes off as dismissive and can easily be lost in translation between the members. Waterbury said in her interview that an inviting cue is like the beginning of a good conversation. ${ }^{134}$ She also mentioned that the main goal for an inviting cue is to create an atmosphere to express the music. ${ }^{135}$

\section{Pre-Cue-Cue}

Before playing, connect with the others in the group and start to think about the tempo and character of the music. ${ }^{136}$ Activate awareness in advance of the cue by feeling the rhythmic character internally.

\section{Über Cue}

“Über,” translated from German, means “over" or "above.” The Über Cue is an exercise using a theatrical cue which is helpful for everyone in the ensemble. ${ }^{137}$ All actions must be either larger than life or very small to exaggerate the character and entrances. The Cavani Quartet insists that the Über Cue should inspire or invite the other members within the group to join. ${ }^{138}$

\footnotetext{
133 Waterbury interview.

134 Waterbury interview.

135 Waterbury interview.

${ }^{136}$ Cotter-Lockard, 104.

${ }^{137}$ Cotter-Lockard, 104.

${ }^{138}$ Cotter-Lockard, "The Art of Collaboration".
} 
"Live, Breathe, and Die": Cueing and Rhythmic Initiation

The "Live, Breathe \& Die" technique enables each member to "be responsible for initiating a passage musically, rhythmically, and dynamically, while other members mirror exactly what they observe." 139 In other words, the responding ensemble members will "Live, Breathe \& Die" for the main initiator. This technique includes looking up once every bar, matching the bow, vibrato, and body movement. Initiating members must be inspiring, inviting, and dramatic. "Live, Breathe, and Die" develops awareness of group communication and listening to others during the performance. This is another Cavani String Quartet rehearsal technique.

\section{Opposite Cue}

Ask the group to cue in a way that they would not want someone to cue them. ${ }^{140}$ This could look like an uninviting cue, like giving the cold shoulder to the other members. Then contrast this with a cue that should be the "correct" way. Another option for opposite cueing is to use big gestures for a fast section or movement or a small gesture for a slow section or movement. ${ }^{141}$ This is the opposite of what Waterbury stated about the general size of the gesture needed for different tempo markings mentioned above. Big gestures can cause some confusion with the group and encourage the cueing member to identify what they can do differently to create a successful cue. Thus, a baseline of what not to do when cueing is established.

\footnotetext{
${ }^{139}$ Cotter-Lockard, "The Art of Collaboration".

${ }^{140}$ Ellis interview.

141 Waterbury interview.
} 


\section{$\underline{\text { IV. Musical Expression }}$}

Although some of the following exercises do not use instruments, they can be just as effective for musical decision-making. Discussions of phrasing, image portrayal, and denoting a "level" of topic, like the Polarities example below, can be beneficial. During these exercises the student does not necessarily need to focus as much on the technical aspects of playing their instruments. The following rehearsal techniques do not need to be applied in every rehearsal but can address issues that involve musical expression that arise during the rehearsal process.

\section{Twice as Fast or Twice as Slow}

Play a section at half tempo or double time. This provides the ensemble a way of understanding how to phrase a particular section because they can sense and hear a "bigger or smaller picture" version of a piece or section.

\section{Imagery}

As a group, visually scan through the piece and pick one or two expressive words to define each section. ${ }^{142}$ This will allow for a more cohesive group sound because everyone will have agreed-upon intentions for a given section. Another option is to find different characters within the sections. This could include comments like, "This section sounds 'icy' to me." The descriptive word 'icy' could signal to the group to use little to no vibrato, be sul tasto (over the fingerboard), and maybe use less body movement.

\footnotetext{
${ }^{142}$ Miró Quartet, "Musical Hourglass.”
} 


\section{Polarities}

The polarities strategy uses a simple 10-point scale to discuss musical elements. ${ }^{143}$ Using the topic of the volume of dynamics as an example, the group would decide where on the scale they would place dynamic volume using a numerical system. The coach could begin with, "Dynamics can be quiet or loud. On a scale from 0 to 10 , how would you describe this section?" Rudoff crafted a diagram similar to this:

\section{Dynamics}

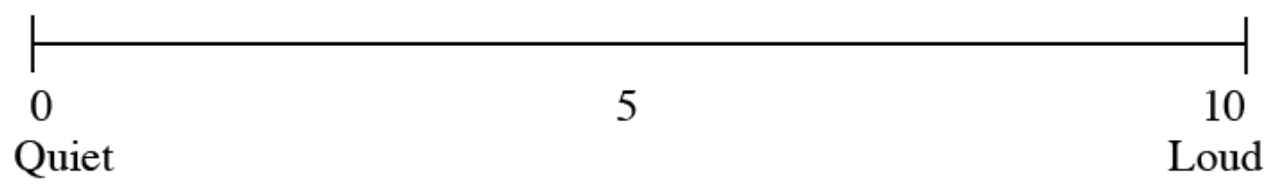

Figure 4.1, Dynamics Graph. ${ }^{144}$

Ultimately, there is no definite answer. The number from 0-10 may change as the group continues to work on their piece. This exercise encourages discussion among the members of the group. Other topics that could be suggested for this exercise might be how to navigate rubato or accelerando, how much freedom of physical movement the quartet is allowed, establishing a character like the 'icy' example from above, among others.

At the end of the research process, it is incredible to see such a list of ideas for this project. Again, this chapter is not intended to be comprehensive, but rather a compilation of rehearsal techniques employed by seasoned performers and award-winning chamber music

\footnotetext{
143 Rudoff interview.
}

${ }^{144}$ Rudoff interview. 
coaches of today. By providing a compilation of this kind, the author seeks to encourage students and teachers to incorporate new ideas into their rehearsals and coachings. 


\section{Chapter 5}

\section{Conclusion}

This research offered a once-in-a-lifetime opportunity to discuss chamber music pedagogy with musicians and coaches that I greatly admire. Through this process I had the chance to reflect deeply on these topics. During the interviews some concepts and ideas were new to me, but I also had the chance to hear many things that were similar to my own experiences. It appeared each of these chamber musicians began performing chamber music at a young age, either with family members or as a young student at summer camp, which is an experience similar to my own and that of many others. With chamber music being a highly collaborative and intimate art form, I believe we all get "bitten by the chamber music bug" because of this simple joy of performing alongside friends and family.

Through the interviews, each participant told stories that brought back memories for them. To my surprise, many of the interviewees had stories involving musical adventures with each other, ranging from working together at the summer chamber music program, to the Castleman Quartet Program, to playing in the faculty groups together at various professional institutions one example being the Ceruti String Quartet at the University of Memphis. Some interviewees mentioned how they learned from each other through their shared experiences and highly respected one another.

While the interviewees seemed pleased to share their experiences they had with their peers, they also brought stories to light that involved some of the most highly regarded quartets of the twentieth century. It struck me afterward that these interviews serve as a bridge from the past great quartets, like the Cleveland Quartet, to today. Even though an hour-long interview is not enough time to capture a person's entire career or knowledge on the topic, we ultimately see 
the inner framework of their personal beliefs of chamber music. While reflecting on Steven Tenebom's statement, previously mentioned in Chapter 1, about how he values chamber music's oral educational traditions, I now feel that this project has been a way for me to honor those oral traditions as a member of the next generation.

Through this research, I have concluded that my original quest to find pedagogical tools that are unique for intermediate players produced a resource that in reality is for players of all levels. As educators, we try to find a common ground of understanding how exercises, techniques, and repertoire form a path from beginner to advanced students. However, many times in chamber music we can come across different playing levels within the ensemble itself more often than not. This is where the importance of teaching the basics of chamber music fundamentals and rehearsal techniques becomes important for every ensemble at every level. Leonard Schranze commented on this in his interview, "[The pedagogical techniques are] all the same, but it is obviously the things you do to get the kids involved." In other words, the information that this resource seeks to provide can be used for many different levels of playing, not only for the intermediate student, and all can find something to improve their performance skills. It is my sincere hope that this project will serve all of those who have a passion for the study and performance of chamber music, and that it will help them to succeed in their musical goals. 
Appendix A: IRB Protocol Approval Letter

\section{WestVirginiaUniversity.}

OFFICE OF HUMAN RESEARCH PROTECTIONS

886 Chestnut Ridge Road Morgantown, WV 26506

Flex Model Approval

$03 / 31 / 2021$

To: Andrea Houde

From: WVU Human Research Protection Program

Protocol Type: NHSR / Flex

Submission Type: Initial

Funding: N/A

WVU Protocol \#: 2103266984

Protocol Title: Chamber Music Fundamentals and Rehearsal Techniques
Approval Date: 03/31/2021

Expiration Date: 03/30/2026

The West Virginia University Institutional Review Board has determined that your submission of protocol 2103266984 qualifies for approval under the WVU Flexibility Review Model.

- FLEX: The review of the above referenced protocol was conducted in accordance with the ethical principles of the Belmont Report. The protocol meets the criteria for approval Flex Model Review because the project does not have federal funding, is considered to be minimal risk, and falls within the guidelines of the WVU Flex Model as of this approval date.

The following documents were reviewed and approved for use as part of this submission. Only the documents listed below may be used in the research. Please access and print the files in the Notes \& Attachments section of your approved protocol.

- IRB Protocol Questions.pdf

- Form-25 IC OMR Cover Letter.docx

- Form-25 IC OMR Cover Letter.pdf

WVU IRB approval of protocol 2103266984 will expire on $03 / 30 / 2026$.

Protocol \#: 2103266984

FWA: 00005078
Phone: 304-293-7073

Fax: 304-293-3098 
1. There is no continuing review option for Flex protocols. If this protocol is still active after five (5) years and you intend to continue, you will need to resubmit a new protocol for approval no less than three (3) weeks prior to the expiration date in order to ensure uninterrupted study continuation.

2. Amendments are not accepted on Flex protocols and are not required as long as there is no increase to risk to participants and changes do not exclude the study from Flex inclusion criteria.

3. The IRB must be notified if there is an increase in risk to participants or if federal funding is awarded to conduct research under this protocol. In any of these cases, this protocol must be submitted as a new submission in WVU+kc.

4. Unanticipated, serious adverse events and/or side effect(s) encountered at WVU or an affiliate site that are related to the research must be reported to the WVU IRB within five (5) days using the Notify IRB action in WVU+kc.

5. Any Unanticipated Problem or UPIRTSO or other research related event resulting in new or increased risk of harm to study subjects, occurring at WVU or an affiliate site, must be reported to the WVU IRB within five (5) days using the Notify IRB action in WVU+kc.

6. All research personnel performing tasks related to the research must complete and remain current for the required training as applicable to the protocol referenced above.

7. Only Flex Consent Forms with the WVU+kc watermark may be used to consent participants.

The WVU Office of Human Research Protections will be glad to provide assistance to you throughout the research process. Please feel free to contact us by phone at 304.293 .7073 or by email at IRB@mail.wvu.edu.

Sincerely,

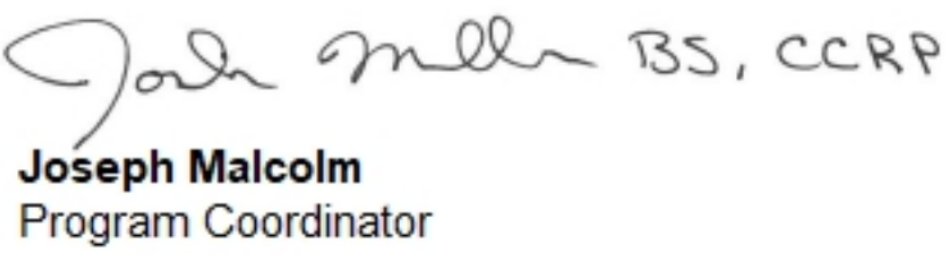


Appendix B: List of Interview Questions

Questions will be selected from this list. Because the questions are open-ended, the conversation may veer.

1. Describe your own chamber music education.

2. What seating arrangement do you use? What influenced this decision?

3. What is your tuning procedure? Do you have a favorite "A"? $(440,441,442)$ Who tunes the quartet/ensemble?

4. What is your strategy for the first rehearsal?

5. What are your favorite rehearsal techniques to use? Any least favorites? Specifically: intonation, articulation, ensemble, balance, group pulse, cueing

6. Do you have any "go-to" problem solvers?

7. Do you use any technology during your rehearsals? Has this technology Changed over the years? What has been the most beneficial? Least beneficial?

8. Any final thoughts on rehearsal techniques? 


\section{Bibliography}

Interviews:

Daetsch, Melinda. Interview with author. May 2021.

Ellis, Erin. Interview with author. June 2021.

Heap, Matthew. Interview with author. May 2021.

Rudoff, Mark. Interview with author. June 2021.

Schranze, Leonard. Interview with author. May 2021.

Waterbury, Susan. Interview with author. June 2021.

Werner, Lauretta. Interview with author. June 2021.

Articles/Books:

Bynong, David M. "24 Chorale Harmonizations by J.S. Bach: Transcribed for String Quartet." American Viola Society, 2016. http://www.americanviolasociety.org/PDFs/Resources/Scores/Bach\%2024\%20Chorales. pdf.

Baron, John H. Intimate Music: A History of the Idea of Chamber Music. Pendragon Press Musicological Series. Stuyvesant, NY: Pendragon Press, 1998.

Bashford, Christina. "Chamber music." Grove Music Online. 2001; Accessed 15 May. 2021. https://www-oxfordmusiconlinecom.wvu.idm.oclc.org/grovemusic/view/10.1093/gmo/9781561592630.001.0001/omo9781561592630-e-0000005379.

Bashford, Christina. "The String Quartet and Society." In The Cambridge Companion to the String Quartet, edited by Robin Stowell, 3-18. Cambridge: Cambridge University Press, 2003.

Bowen, José A. "Stokowski, Leopold." Grove Music Online. 2001; Accessed 31 Oct. 2021. https://www-oxfordmusiconlinecom.wvu.idm.oclc.org/grovemusic/view/10.1093/gmo/9781561592630.001.0001/omo$9781561592630-\mathrm{e}-0000026825$.

Cavani String Quartet. "Cavani String Quartet Celebrates 30 Years as Artists-In Residence at the Cleveland Institute of Music 1988-2018.” News. Accessed November 18, 2021. https://cavanistringquartet.com/news/cavani-string-quartet-celebrates-30-years-artistsresidence-cleveland-institute-music-1988-2018/. 
Churgin, Bathia. "Sammartini [S. Martino, S. Martini, St. Martini, St. Martino, San Martini, San Martino, Martini, Martino], Giovanni Battista." Grove Music Online. 2001; Accessed 19 May. 2021. https://www-oxfordmusiconlinecom.wvu.idm.oclc.org/grovemusic/view/10.1093/gmo/9781561592630.001.0001/omo9781561592630-e-0000024463.

Cue, n.2". OED Online. September 2021. Oxford University Press. https://www-oedcom.wvu.idm.oclc.org/view/Entry/45574?rskey=Hbwfew\&result=2\&isAdvanced=false (accessed November 20, 2021).

Eisen, Cliff, Antonio Baldassarre, and Paul Griffiths. "String Quartet." Grove Music Online. 2001; Accessed 15 May. 2021. https://www-oxfordmusiconlinecom.wvu.idm.oclc.org/grovemusic/view/10.1093/gmo/9781561592630.001.0001/omo9781561592630-e-0000040899.

Feder, Georg, and James Webster. "Haydn, (Franz) Joseph." Grove Music Online. 2001; Accessed 19 May. 2021. https://www-oxfordmusiconlinecom.wvu.idm.oclc.org/grovemusic/view/10.1093/gmo/9781561592630.001.0001/omo9781561592630-e-0000044593.

Finck, Ledah. "Pedagogical Works." Compositions. Accessed November 16, 2021. https://www.ledahfinck.com/compositions.

da Fonseca-Wollheim, Corinna. "Twisting for Solos, the Violist Is a Quartet's Odd Player Out." New York Times, August 31, 2018, https://www.nytimes.com/2018/08/31/arts/music/string-quartet-viola.html.

Fullard, Annie, and Dorianne Cotter-Lockard. "The Art of Collaboration: Creative Chamber Music Rehearsal Techniques \& Musical Team Building.” Cavani String Quartet. 2020. https://cavanistringquartet.com/art-collaboration-seminar/.

Gebrian, Molly. "Interleaved Practice: The Best Practice Method for Reliable Performance." Journal of the American Viola Society 32, no. 2 (Fall 2016): 37-42.

Gloag, Kenneth. "The String Quartet in the Twentieth Century." In The Cambridge Companion to the String Quartet, edited by Robin Stowell, 288-309. Cambridge: Cambridge University Press, 2003.

Goldman, Richard Franko. "Current Chronicle". Musical Quarterly 37, no. 1 (January 1951): 83-89.

Griffiths, Paul. The String Quartet. New York: Thames and Hudson, 1983.

"Intermediate, adj. and n.". OED Online. June 2021. Oxford University Press. https://www-oedcom.wvu.idm.oclc.org/view/Entry/97980?isAdvanced=false\&result=1\&rskey=uXEVtY \& (accessed July 05, 2021). 
Jones, David Wyn. “The Origins of the Quartet." In The Cambridge Companion to the String Quartet, edited by Robin Stowell, 177-184. Cambridge: Cambridge University Press, 2003.

Knittel, K.M. "Schuppanzigh, Ignaz." Grove Music Online. 2001, https://wwwoxfordmusiconlinecom.wvu.idm.oclc.org/grovemusic/view/10.1093/gmo/9781561592630.001.0001/omo9781561592630-e- 0000025160.

Ledbetter, Steven. "Kneisel Quartet." Grove Music Online. 2001; Accessed 18 May. 2021. https://www-oxfordmusiconlinecom.wvu.idm.oclc.org/grovemusic/view/10.1093/gmo/9781561592630.001.0001/omo9781561592630-e-0000046769.

Lener, Jeno. The Technique of String Quartet Playing: Score and Parts. London: Chester, 1935.

Loft, Abram, and Reinhard G Pauly. Ensemble!: A Rehearsal Guide to Thirty Great Works of Chamber Music. Portland: Amadeus Press, 1992.

Loft, Abram. How to Succeed in an Ensemble: Reflections on a Life in Chamber Music. Portland: Amadeus Press, 2003.

Mangsen, Sandra. "Trio Sonata." Grove Music Online. 2001; Accessed 27 May. 2021. https://www-oxfordmusiconlinecom.wvu.idm.oclc.org/grovemusic/view/10.1093/gmo/9781561592630.001.0001/omo9781561592630-e-0000028382.

Miró Quartet. “Musical Hourglass.” 1999. Handout.

Norton, M. D. Herter. The Art of String Quartet Playing: Practice, Technique, and Interpretation. New York: Simon and Schuster, 1962.

Norton, M. D. Herter. String Quartet Playing: A New Treatise on Chamber Music, Its Technic and Interpretation. New York: C. Fischer, 1925.

Parker, Mara E. "Rehearsal Techniques and Advice." In String Quartets: A Research and Information Guide, 407-11. London: Routledge, 2011.

Pochon, Alfred. A Progressive Method of String-Quartet Playing in Two Parts. New York: G. Schirmer, 1924. http://catalog.hathitrust.org/api/volumes/oclc/68156241.html.

Potter, Tully. "From Chamber to the Concert Hall." In The Cambridge Companion to the String Quartet, edited by Robin Stowell, 58. Cambridge: Cambridge University Press, 2003. 
Radice, Mark A. Chamber Music: An Essential History. Ann Arbor: University of Michigan Press, 2012. Accessed May 15, 2021. ProQuest Ebook Central.

Roy André J. String Quartet Technique. Montreal: Royalto Edition, 2014.

Rudoff, Mark. "In Order to Form a More Perfect Union: Enacting a Constitution for a Chamber Group.” American String Teachers Journal 50, no. 4 (November 2000): 72-9.

Scott, Heather K. "Refine Your Ensemble's Sound by Hiring a Coach.” Strings 26 no. 5 (December 2011): 37-8.

Scott, Heather K. "5 Ways to Make the Most Out of Your Rehearsal Time." Strings 26, no. 6 (January 2012): 35-6.

Scott, Hugh Arthur. "London's Earliest Public Concerts." The Musical Quarterly 22, no. 4 (1936): 457. Accessed May 14, 2021. http://www.jstor.org/stable/738953.

Selby, Christopher R. Habits of a Successful Orchestra Director. Chicago: GIA Publisher Inc., 2016.

Selby, Christopher R. "Habits of a Successful School Orchestra - Giamusic.com.” GIA Publisher, Inc. Accessed November 1, 2021. https:/www.giamusic.com/pdf/8628HO1Strings.pdf.

Shaffer, Karen A. "Powell, Maud." Grove Music Online. 2001; Accessed 17 Jun. 2021. https://www-oxfordmusiconlinecom.wvu.idm.oclc.org/grovemusic/view/10.1093/gmo/9781561592630.001.0001/omo$9781561592630-\mathrm{e}-0000043691$.

Spinosa, Frank and Harold W. Rusch. Fine Tuning: 50 Intermediate String Ensembles for Developing Solid Intonation and Tone Production. San Diego: Neil A. Kjos Music Company, 1989.

Standage, Simon. "Historical Awareness in Quartet Performance.” In The Cambridge Companion to the String Quartet, edited by Robin Stowell, 127-148. Cambridge: Cambridge University Press, 2003.

Unverricht, Hubert and Cliff Eisen. "Divertimento." Grove Music Online. 2001; Accessed 5 Dec. 2021. https://www-oxfordmusiconlinecom.wvu.idm.oclc.org/grovemusic/view/10.1093/gmo/9781561592630.001.0001/omo$9781561592630-\mathrm{e}-0000007864$.

Webster, James. "Violoncello and Double Bass in the Chamber Music of Haydn and His Viennese Contemporaries, 1750-1780." Journal of the American Musicological Society 29, no. 3 (1976): 413-38. 
Wilson, Miranda. "The Path to Success as a String Quartet: The Dover Quartet Offers 8 Career Tips to Aspiring Chamber Ensembles.” Strings 30, no. 2 (September 2015) 71-4. https://www.doverquartet.com/features/2015/8/28/strings-magazine.

Audio/Video:

foxfireman188. “A Night in Tunisia - Turtle Island String Quartet.” YouTube Video, 8:12.

December 20, 2021. https://www.youtube.com/watch?v=XyDE26kle2A.

ohyoi23. "Purple Haze - Kronos Quartet.” YouTube Video, 4:29. June 17, 2011. https://www.youtube.com/watch?v=4dE65iTuG4Y.

Blog:

Finckel, David. David Finckel and Wu Han Blog (blog). An Open Letter: Prepare for Your Chamber Coaching. https://artistled.wordpress.com/2010/01/06/students/.

Database:

American Viola Society. "Underrepresented Composer Database.” Accessed May 1, 2021. https://www.americanviolasociety.org/Composer-Database/Search.php.

Dissertations:

Cotter-Lockard, Dorianne. "Chamber Music Coaching Strategies and Rehearsal Techniques that Enable Collaboration." PhD diss. Fielding Graduate University, 2012.

Images:

"The Joachim Quartet, Berlin, 1898." Digital image. https://josephjoachim.com. August 4, 2014. Accessed May 22, 2021.

Kamfest, “TICC 2013 Quartet Berlin-Tokyo.” Digital image. https://commons.wikimedia.org/wiki/File:TICC_2013_Quartet_Berlin-Tokyo.jpg. September 26, 2013. Accessed December 5, 2021.

Princess Ruto. “Arianna String Quartet.” Digital image. https://commons.wikimedia.org/wiki/File:Arianna_String_Quartet_(14193354501).jpg. April 28, 2014. Accessed December 5, 2021.

Websites:

BandLab. “About Us.” Accessed June 4, 2021. https:/www.bandlab.com/.

Fischoff. "Congratulations to the Winners." Accessed May 28, 2021. https://www.fischoff.org/news/congratulations-to-the-winners/. 